\title{
Hydrodynamic changes imposed by tidal energy converters on extracting energy on a real case scenario

\author{
Pacheco, A. ${ }^{*}$, Ferreira, Ó. ${ }^{1}$ \\ ${ }^{1}$ CIMA/Universidade do Algarve, Edifício 7, Campus de Gambelas Faro, 8005-139, Portugal, ampacheco@ualg.pt, \\ oferreir@ualg.pt
}

\begin{abstract}
The development on tidal turbine technology is ongoing with focus on several aspects, including hydrodynamics, operation and environment. Before considering an area for exploitation, tidal energy resource assessments in pre-feasibility energy extraction areas must include the relevant characteristics of the device to be used. The present paper uses the momentum source approach to represent a floatable tidal energy converter (TECs) in a coastal hydro-morphodynamic model and to perform model simulations utilising different TEC array schemes by quantifying the aggregated drag coefficient of the device array. Simulations for one-month periods with nested models were performed to evaluate the hydrodynamic impacts of energy extraction using as output parameters the reduction in velocity and water-level variation differences against a no-extraction scenario. The case study focuses on representing the deployment of floatable E35 Evopod TECs in Sanda Sound (South Kintyre, Argyll, Scotland). The range in power output values from the simulations clearly reflects the importance of choosing the location of the array, as slight changes in the location (of $<1 \mathrm{~km}$ ) can approximately double the potential power output. However, the doubling the installed capacity of TECs doubles the mean velocity deficit and water-level differences in the area surrounding the extraction point. These differences are amplified by a maximum factor of 4 during peak flood/ebb during spring tides. In the simulations, the drag coefficient is set to be constant, which represents a fixed operational state of the turbine, and is a limitation of coastal models of this type that cannot presently be solved. Nevertheless, the nesting of models with different resolutions, as presented in this paper, makes it possible to achieve continuous improvements in the accuracy of the quantification of momentum loss by representing turbine characteristics close to the scale of the turbine.
\end{abstract}

Keywords: Tidal energy; Tidal energy converters; Floatable tidal turbines; Hydrodynamic modelling; Sanda Sound, Scotland. 


\section{Introduction}

The hydrokinetic energy that can be extracted from tidal currents is one of the most promising renewable energy sources [1]. Tidal energy extraction is very site specific, that is, the methods for determining the limits of and potential for energy extraction from a channel differ from site to site. Although the effects of removing energy may not be detectable when one or even ten tidal turbines are concerned, extracting tidal energy at commercial scales can potentially have several impacts on the environment, including a reduction in tidal amplitude, disruptions to flow patterns and concomitant changes in the transportation and deposition of sediments, changes in the population distributions and dynamics of marine organisms, modifications to water quality and marine habitats, increases in ambient noise, and greater levels of mixing in systems in which salinity and temperature gradients are well defined [2-7]. Disruptions to flow patterns may also have consequences for the downdrift energy extraction potential, endangering implementation schemes and their efficiency; for example, the efficiency of a Tidal Energy Converter (TEC) positioned in the wake of another device within TEC array schemes.

An understanding of the hydrodynamic shifts induced by TEC devices can be obtained through the use of numerical modelling techniques, calibrated using databases for different test case sites. When modelling the flow across turbines, a decision has to be made about how the properties of TECs should be represented in the coastal model, that is, how the drag forces associated with power extraction are modelled. The representation of those forces aims to "upscale" the effects of the detailed flow and turbulence around a simplified turbine to give a coarse representation of the hydrodynamic forces acting on a turbine or on a group of turbines [8]. In the open source Delft3D model, this can be effectively performed using porous plates by analogy with the actuator disc theory. The data needed for applying this approach require the determination of a momentum loss term able to represent the extraction of energy from the free flow. Ideally, this loss term should be determined by analysing the turbulence scales and velocity profile distortion under different flow conditions while operating TECs in real conditions. However, because the availability of data on operating TECs in real conditions is scarce, the momentum loss term is calculated based on TEC prototype characteristics, physical assumptions, and/or data collected from testing scale models in physical tanks. Prior to adding the momentum loss term into the modelling equations 
and evaluating different energy extraction scenarios based on simulations, the numerical models first need to reproduce the hydro-morphodynamic characteristics of the area of interest.

This paper presents the methods for setting up the Delft3D model at Sanda Sound, South Kintyre Peninsula (Argyll, Scotland) to gain realistic insights into the hydrodynamic impacts of energy extraction in confined channels and to consider different solutions for effectively simulating energy extraction with reference to the installation of an array of devices (E35 Evopods) within the study area. The paper explains the modelling set-up, the calibration factors used, and the validation procedures adopted both before and after incorporating turbine effects. The turbine characteristics were obtained using drag data from prototype testing in both physical tanks and real conditions. These values were used for determining the momentum loss term induced by the energy extraction, which was then implemented on the numerical mesh via porous plates and using appropriate scaling factors. This procedure allowed the momentum loss term derived from the energy extraction of an idealised array scheme to be determined and simulations to evaluate the potential impacts of energy extraction on flow patterns to be performed.

The novelty of the present paper can be stressed by two main points: (1) this is the first paper trying to model floatable tidal devices (e.g. such as the Evopod) on a numerical modelling using the aggregate drag approach to reproduce the effects of energy extraction by an array scheme. The attempt relates directly to the local 1MW project that is predicted to future be implemented at Sanda Sound; and (2) the methodology used to achieve the proposed goals is focused on the use of coupled nested models using Delft3D Dashboard, an approach that can be easily implemented elsewhere. Although direct comparisons with experimental data will be carried on soon as the prototype is fully functional on the water, the present paper addresses the challenges of setting up a model on a remote coastline such as Sanda Sound making the best use of the available information (e.g. coupling available bathymetric and hydrodynamic data, existing data on Evopod testing in the Newcastle wave-current-wind tank and on the real case scenario of Strangford Lough). Those tests allowed determining the drag forces associated with energy extraction from the free flow, which complemented the available data on the characteristics of the 1:4 Evopod prototype (E35 kW). 
100

101

102

103

104

105

106

107

108

109

110

111

112

113

\section{Study case}

\subsection{Site characteristics}

The study site is Sanda Sound, which is located off the Mull of Kintyre in southwest Scotland (Fig. 1). Sanda Sound is a channel that flows between Sanda Island and the Kintyre Peninsula, and connects the North Channel to the Firth of Clyde. The North Channel is the strait between northeastern Ireland and southwestern Scotland; it connects the Irish Sea with the Atlantic Ocean, and is part of the marine area officially classified as the "Inner Seas off the West Coast of Scotland" by the International Hydrographic Organization (IHO). The minimum width of the channel of $21 \mathrm{~km}$ is located between the Mull of Kintyre (the southwest point of Kintyre Peninsula, Scotland) and Torr Head (Northern Ireland). The Firth of Clyde is the largest and deepest area of coastal water in the British Isles, and is sheltered from the Atlantic Ocean by the Kintyre Peninsula.


Figure 1. (A) Map of Scotland with small box (bottom left) depicting the location of the test site, Sanda Sound; (B) Admiralty Chart 2126 marking the location of the Evopod E35 mooring (circle)

\subsection{Oceanographic setting}

Scotland's location in the northern part of the British Isles and the steep bathymetry of the continental slope together act as a barrier between the oceanic regions and the shelf sea systems, reducing the amount of water that is able to move from the deeper waters of the North Atlantic into the shallower waters of the Scottish continental shelf. 
123 Scotland has a maritime climate that is strongly influenced by the oceanic waters of the

124 North Atlantic and the prevailing southwesterly winds. As these winds blow over the regions of the North Atlantic, warmed by the North Atlantic Current, they pick up heat that gives Scotland a relatively mild, wet climate considering its latitude [9].

The wave climate of Scotland is influenced mainly by conditions in the North Atlantic Ocean, where the fetch is sufficiently long to establish large, regular waves (i.e., swell) [10]. The north and west of Scotland (the Hebrides, Orkney Islands, and Shetland Islands) are most exposed to these conditions [11,12]. Wave heights are greatest in the most exposed waters of the north and west, and decrease markedly into the North Sea and southwards from there into both the Irish Sea and the English Channel [13]. Within the Irish Sea, the waves tend to be locally generated, have fairly short periods (50-yr mean values in the order of $10 \mathrm{~s}$ within the Irish Sea and $15 \mathrm{~s}$ at its outer entrances), and are relatively large (50-yr significant wave heights ranging from $8 \mathrm{~m}$ within the Irish Sea to $12 \mathrm{~m}$ at its entrances) [14]. Sanda Sound is protected from NW waves because of Kintyre Peninsula, but is relatively exposed to W-SW waves of 2-3 m amplitude that propagate into the sound in the winter months [15].

Overall, the tidal range along Scotland's coast is generally between 4 and $5 \mathrm{~m}$, with the highest tidal ranges being found in the inner Solway Firth where the mean spring tidal range lies between 7 and $8 \mathrm{~m}$ [9]. The tidal range is a minimum between Islay and the Mull of Kintyre and in the northeastern North Sea (amphidromic points). The tidal range at Sanda Sound is indicated on the Admiralty Chart to be $2.8 \mathrm{~m}$ at spring tides. The tidal currents are intensified in localised areas, usually where the flow is constrained by topography. This includes areas such as between the Orkney Islands and Shetland Islands, the Pentland Firth, off the Mull of Kintyre, and the Hebrides, where tidal streams can be as high as $3.5-4.5 \mathrm{~ms}^{-1}$. In particular, the tidal current speeds within Sanda Sound are 2.0-2.5 $\mathrm{ms}^{-1}$, ideal for tidal stream devices.

\subsection{Tidal energy conversion device}

On 7 August 2014, the company Oceanflow Development Limited (ODL) deployed a 1:4 scale semi-submerged mono-turbine, the E35 Evopod ${ }^{\mathrm{TM}}$ [16], in Scottish waters at Sanda Sound (Fig. 2). The ODL technologies, namely, a turbine generator system and the mono-turbine support platform, are at Technology Readiness Level (TRL) 7. 
Testing a grid-connected unit at a site that combines tidal stream currents with a realistic wave environment will allow this ODL technology to evolve to TRL 9. The E35 uses a simple mooring and power-export solution that allows the free-floating device to maintain optimum heading into the direction of flow (tidal stream, river, or ocean current). The turbine has four fixed-pitch blades with a rotor diameter of $4.5 \mathrm{~m}$, and its semi-submerged support platform has a length of $13 \mathrm{~m}$, a beam of $4.5 \mathrm{~m}$, a height of $8 \mathrm{~m}$, a displacement of 13 tonnes, and a rated output of $35 \mathrm{~kW}$.

The E35 is connected to the grid via a flexible umbilical cable running from the device to the seabed. Energy from the E35 device is transmitted ashore via a seabed cable that is connected to the $11-\mathrm{kW}$ grid and to the onshore control cabin. The E35 is equipped with load cells placed on the mooring lines to measure the tension of the Evopod while extracting energy, as well as with flow speed ultrasonic sensors, a GPS, a weather station, a CCTV and underwater camera, and several devices for measuring performance parameters (e.g., RPM, torque, and power). The location of deployment of the E35 device is approximately $800 \mathrm{~m}$ off the Kintyre shoreline in $22 \mathrm{~m}$ water depth. The principal characteristics of the E35 prototype are given in Table 1.

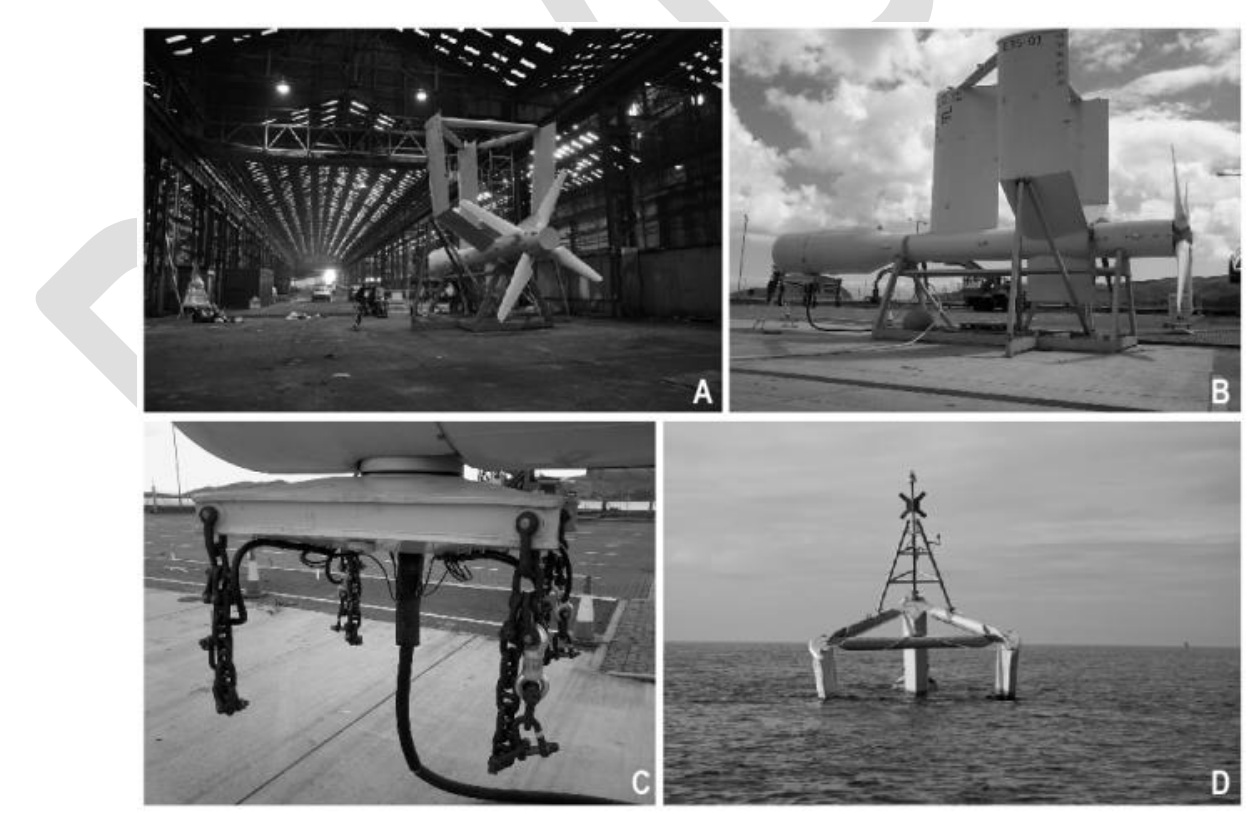

Figure 2. (A) The Evopod E35 being built at Glasgow shipyards; (B) E35 seating at Campbeltown harbour; (C) the E35 is tethered to the sea bed using a 4-point catenary spread mooring system with simple pin-pile or gravity anchors. The E35 rotates on its mooring so that it is always aligned with the flow; (D) deployment of the E35 at Sanda Sound at the mooring location indicated in Figure 1. 
Table 1. Evopod E35 specifications of the 1:4 scale model deployed at Sanda Sound (South Kintyre, Scotland).

\begin{tabular}{lc}
\hline Parameter & Value \\
\hline Number of blades (N) & 4 \\
Length (m) & 13 \\
Height (m) & 8 \\
Beam (m) & 4.5 \\
Weight of superstructure (tonnes) & 10.4 \\
Weight of power take-off equipment (tonnes) & 2.6 \\
Min. installation depth (m) & 16 \\
Max. installation depth (m) & No limit \\
Design lifetime (years) & 20 \\
Cut in speed (ms ${ }^{-1}$ ) & 0.7 \\
Rated flow speed (ms ${ }^{-1}$ ) & 2.3 \\
Rated power (kW) at rated flow speed & 35 \\
Maximum flow speed (ms ${ }^{-1}$ ) & 3.2 \\
\hline
\end{tabular}

181

The deployment of the E35 at Sanda Sound is a unique opportunity to understand the long-term performance of a floating, tethered turbine in an energetic tidal-flow environment, as ODL holds a 7-year lease from The Crown Estate to operate the device. The E35 displays a navigation light (flashing yellow in a $360^{\circ}$ sweep at a 5-s interval) and a yellow St Andrews Cross on its mast (marked as such on Admiralty Chart 2126, Fig. 1B). Vessels can therefore pass Evopod $^{\mathrm{TM}}$ units just as they would pass a navigation buoy. Since its deployment, the trials have demonstrated the Evopod's low levels of motion and robustness at the moderately fast flowing tidal site (http://www.oceanflowenergy.com/news26.html), which in the winter months is also exposed to a harsh wave environment emanating from the Atlantic Ocean and Irish Sea. The streamlined surface-piercing struts and turret mooring of the floating platform ensure that the device always faces into the flow whatever the wave direction, and the small water-plane area of the struts and the deeply submerged tubular hull of the device ensure that the buoy has very low levels of motion compared with more conventional surface-floating platforms or buoys (Fig. 2).

\section{Methods}

\subsection{Numerical Modelling Using Delft3D}

Delft3D-Flow (Delft Hydraulics) is a multi-dimensional hydrodynamic (and transport) simulation programme that calculates non-steady flow and transport phenomena resulting from tidal and meteorological forcing on a rectilinear or curvilinear boundary- 
203 fitted grid. The model is a finite difference code that solves the baroclinic Navier-

204 Stokes and transport equations under shallow-water and Boussinesq assumptions [17].

205 The hydrostatic shallow-water equations, expressing the conservation of mass and

206 momentum, are given in Cartesian rectangular coordinates in the horizontal by:

$207 \quad \frac{\partial \xi}{\partial t}+\frac{\partial[(d+\zeta) U]}{\partial x}+\frac{\partial[(d+\zeta) V]}{\partial y}=Q$

$208 \frac{\partial U}{\partial t}+U \frac{\partial U}{\partial x}+V \frac{\partial U}{\partial y}-f V=-g \frac{\partial \xi}{\partial x}-\frac{g}{\rho_{0}} \int_{-d}^{\zeta} \frac{\partial \rho^{\prime}}{\partial x} d z+\frac{\tau_{s x}-\tau_{b x}}{\rho_{0}(d+\varsigma)}+v_{h} \nabla^{2} U$

$209 \frac{\partial V}{\partial t}+U \frac{\partial V}{\partial x}+V \frac{\partial V}{\partial y} \mp f U=-g \frac{\partial \xi}{\partial y}-\frac{g}{\rho_{0}} \int_{-d}^{\zeta} \frac{\partial \rho^{\prime}}{\partial y} d z+\frac{\tau_{s y}-\tau_{b y}}{\rho_{0}(d+\varsigma)}+v_{h} \nabla^{2} V$

210 where: $\zeta(x, y)$ is the water level above a reference plane; $\xi$ are the horizontal 211 coordinates; $d(x, y)$ is the depth below the reference plane; $U$ and $V$ are the vertically 212 integrated velocity components in the $x$ and $y$ directions, respectively; $Q$ represents the 213 intensity of mass sources per unit area (i.e., the contributions per unit area due to the 214 discharge or withdrawal of water, precipitation, and evaporation); $f$ is the Coriolis 215 parameter; $g$ is the gravitational acceleration; $v_{h}$ is the horizontal eddy viscosity 216 coefficient; $\rho_{o}$ and $\rho^{\prime}$ are the reference and anomaly densities, respectively; $\tau_{b x}$ and $\tau_{b y}$ 217 are the shear stress components at the bottom; and $\tau_{s x}$ and $\tau_{s y}$ are the shear stress 218 components at the surface. The vertical velocity $(W)$ is obtained from the continuity 219 equation:

221 Two models were set up through Delft Dashboard, a stand-alone Matlab-based 222 graphical user interface coupled to the Delft3D modelling suite (Deltares) that allows 223 computations for hydrodynamics, waves, and morphodynamics to be made. The first 224 model is a coarse model with a resolution of $1 \mathrm{~km}$ covering the Irish Sea and extending 225 out to the Outer Hebrides (Fig. 3A). The second model is a medium-resolution model of 226 Kintyre Peninsula with a cell spacing of $250 \mathrm{~m}$ (Fig. 3B). The reason for choosing two 227 independent models was to create a nested model, using better and more realistic 228 boundary conditions for the medium-resolution model than was used for the coarse229 resolution run. 


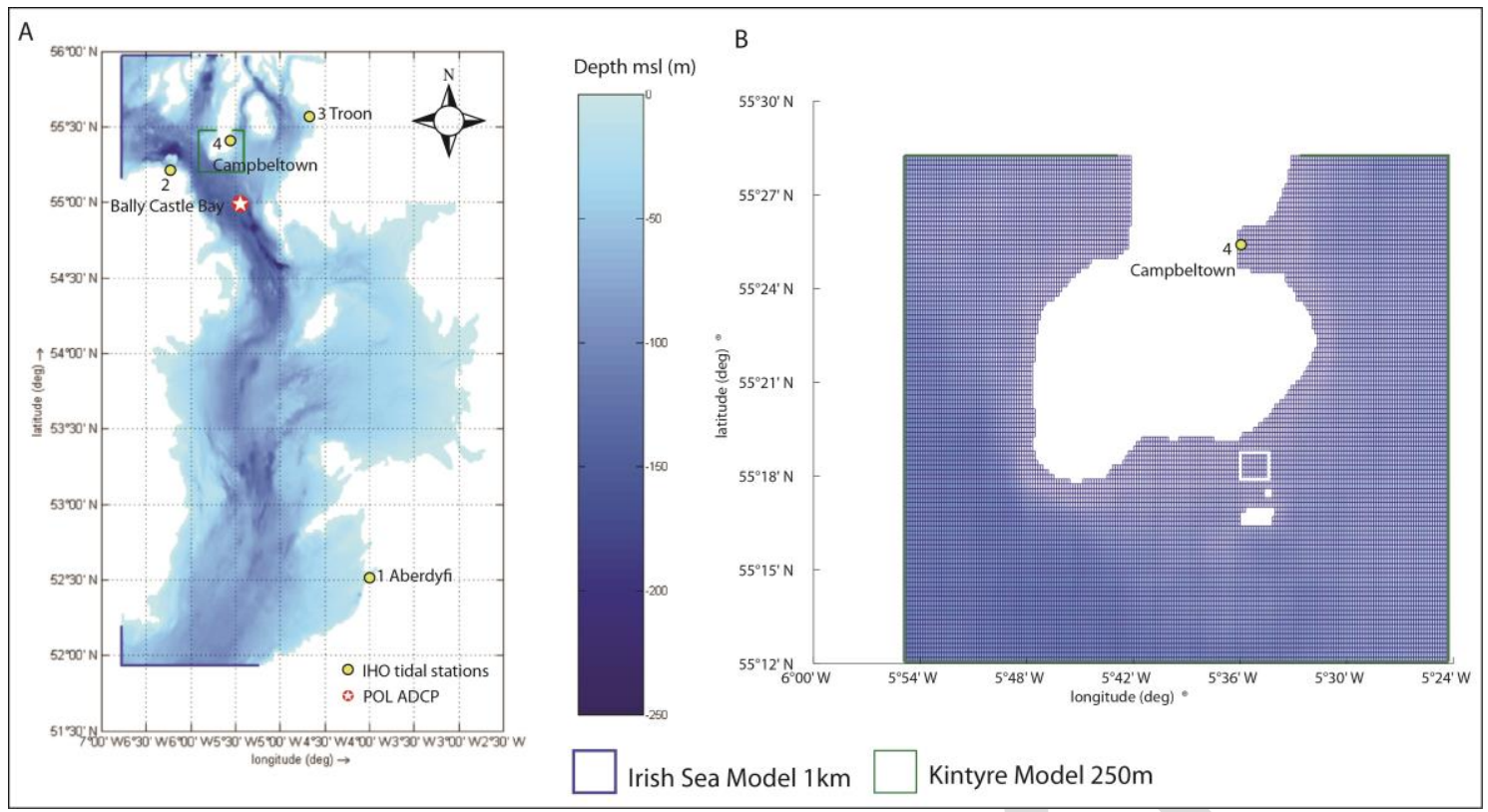

Figure 3. (A) Irish Sea numerical grid set-up with the prescribed model boundaries and 1-km resolution; (B) a zoom-in to the area of interest, Sanda Sound, Kintyre Peninsula with a 250-m-resolution grid, with the white box representing the area of interest for the deployment of an array of E35 devices.

To set up both models, rectilinear orthogonal grids in Cartesian coordinates were built using Delft dashboard utilities and a compilation of available bathymetric data. It is important to note that the chosen model resolutions are uniquely related to the available bathymetry data and can therefore be further improved when high-resolution data are available (for example, multi-beam bathymetry would provide a resolution of $2 \mathrm{~m}$ and would allow a model to be nested at the turbine scale). The vertical resolution is provided via sigma level coordinates to allow for a free surface. The datasets used for modelling set-up are described in Table 2. The coarse-resolution study domain was divided by $410 \times 406$ grid points in the $M$ and $N$ directions, respectively, resulting in grid cell dimensions of $1 \mathrm{~km} \times 1 \mathrm{~km}$. At the model boundary (blue lines in Fig. 3A), the sea level was prescribed using the ranges of the main tidal constituents by computing the tidal elevation at the boundaries for each time step. The Delft dashboard has a 'Tide Stations' toolbox (using both IHO and XTide stations) that allows the user to both view and download water-level time series derived using astronomical constituents for a selected tidal station and to directly define observation points in Delft3D-Flow.

251 The finer resolution was divided by $206 \times 110$ grid points in the $M$ and $N$ directions, respectively, resulting in grid cell dimensions of $250 \mathrm{~m} \times 250 \mathrm{~m}$. At the open boundary (green line in Fig. 3B), the water level was prescribed using the ranges of the time- 
series values outputted from the coarse model run for each time step. Both models were run on 3D mode with 3-sigma levels and the time step used was $15 \mathrm{~s}$, which, according to the Courant-Friedrichs-Levy criterion, is sufficiently small to ensure numerical stability. The spatial discretisation of the horizontal advection terms was carried out using the cyclic method, and time integration was based on the ADI method [18].

Table 2. Datasets used for the modelling set-up.

\begin{tabular}{|c|c|c|}
\hline Type of Data & Details & Source \\
\hline \multirow[t]{2}{*}{ Bathymetry } & $\begin{array}{l}\text { 2014. General Bathymetric Chart of the Oceans } \\
\text { (GEBCO) } \\
\text { Coverage: Irish Sea }\end{array}$ & $\begin{array}{c}\text { International Hydrographic } \\
\text { Organization, Intergovernmental } \\
\text { Oceanographic Commission, and } \\
\text { others }\end{array}$ \\
\hline & Resolution: 30 arc-second interval grid $\sim 1 \mathrm{~km}$ & \\
\hline \multirow{3}{*}{ Bathymetry } & $\begin{array}{l}\text { 2014. European Marine Observation and Data } \\
\text { Network (EMODNet) }\end{array}$ & $\begin{array}{c}\text { EMODNet Bathymetry portal - } \\
\text { http://www.emodnet-bathymetry.eu }\end{array}$ \\
\hline & Coverage: Irish Sea & National Oceanography Centre \\
\hline & Resolution: $250 \mathrm{~m}$ & OceanWise Limited \\
\hline \multirow{3}{*}{ Bathymetry } & 2012. Multibeam H1355. & UK Hydrographic Office \\
\hline & Coverage: Kintyre & \\
\hline & Resolution: $2 \mathrm{~m}$ & \\
\hline Currents & $\begin{array}{c}\text { 1993. Upward-looking, bottom-mounted ADCP } \\
\text { Site (54 } 59.83 \mathrm{~N}, 05^{\circ} 29.96 \mathrm{~W} \text {, water depth } 139 \\
\text { m, Fig. 3). Part of a collection of sites used in } \\
\text { the North Channel experiment (Challenger } \\
\text { Cruises) }\end{array}$ & $\begin{array}{l}\text { Proudman Oceanographic Laboratory } \\
\text { (now National Oceanography Centre) }\end{array}$ \\
\hline Water levels & 2015. Tidal gauge stations & $\begin{array}{c}\text { International Hydrographic } \\
\text { Organization, Intergovernmental } \\
\text { Oceanographic Commission and } \\
\text { others }\end{array}$ \\
\hline
\end{tabular}

262 The water levels were computed at grid cell centres and velocity components were defined at the midpoints of the grid cell faces (i.e., Arakawa-C staggered grids). The horizontal large-eddy simulation (HLES) model for simulating horizontal turbulence was combined with the use of the $k-\varepsilon$ turbulence model. HLES assumes that the small-scale turbulent motions are isotropic, that is, they are not affected by large-scale geometry. Because the objectives of the present work were to test the model sensitivity in order to represent the far-wake modification related to tidal energy extraction, the Delft3D-Flow module was run without wind and wind-wave forcing. The physical and numerical parameters chosen for each model are provided in Table 3. 
Table 3. Delf3D parameters for the hydro-morphodynamic transport model.

\begin{tabular}{|c|c|c|}
\hline Parameters & Model 1 & Model 2 \\
\hline Resolution & $1 \mathrm{~km}$ & $250 \mathrm{~m}$ \\
\hline Coordinate system & Sigma & Sigma \\
\hline Grid points in $\mathrm{M} \times \mathrm{N}$ Directions & $410 \times 406$ & $206 \times 110$ \\
\hline Number of layers & 3 & 3 \\
\hline Time step & $15 \mathrm{~s}$ & $15 \mathrm{~s}$ \\
\hline Forcing type & Astronomical (IHO stations) & $\begin{array}{l}\text { Water-level time series generated } \\
\text { from Model } 1\end{array}$ \\
\hline Reflection parameter alpha $\left(s^{2}\right)$ & 1000 & 1000 \\
\hline Water density $\left(\mathrm{kgm}^{-3}\right)$ & 1025 & 1025 \\
\hline Gravity $\left(\mathbf{m}^{2} \mathbf{s}^{-1}\right)$ & 9.81 & 9.81 \\
\hline Roughness $\left(\mathbf{m}^{1 / 2} \mathbf{s}^{-1}, \text { Chezy }\right)^{*}$ & 100 & 100 \\
\hline Horizontal eddy viscosity $\left(\mathrm{m}^{2} \mathrm{~s}^{-1}\right)$ & 10 & 1 \\
\hline $\begin{array}{l}\text { Horizontal eddy diffusivity ( } \mathrm{m}^{2} \\
\mathrm{~s}^{-1} \text { ) }\end{array}$ & 10 & $\mathrm{n} / \mathrm{a}$ \\
\hline Vertical eddy viscosity $\left(\mathrm{m}^{2} \mathrm{~s}^{-1}\right)$ & $\mathrm{n} / \mathrm{a}$ & 1 \\
\hline $\begin{array}{l}\text { Model for 2D turbulence } \\
\text { Model for 3D turbulence }\end{array}$ & $\begin{array}{l}\text { Sub-grid scale HLES } \\
\text { n/a }\end{array}$ & $\begin{array}{l}\text { Sub-grid scale HLES } \\
\text { k-Epsilon }\end{array}$ \\
\hline
\end{tabular}

The Irish Sea hydrodynamic model was validated against a moored Acoustic Doppler Current Profiler (ADCP) south of Kintyre Peninsula (5459.83N, 05²9.96W, water

277 depth $139 \mathrm{~m}$ ) deployed by the Proudman Oceanographic Laboratory (now National 278 Oceanography Centre, Liverpool) under the POL North Channel Experiment 279 (Challenger Cruises C106 and C107). The ADCP (Fig. 3A) was deployed at a fixed depth $(139 \mathrm{~m})$, and ENU velocity components were measured from the sensor over a range of depths every $10 \mathrm{~min}$ (cell size $=8 \mathrm{~m}$ ). The equipment return $78 \%$ of good data collecting instantaneous velocities between 24-127 m due to the side lobe interference at surface (no data between 0-24 m) and blanking (no data between 127-139 m). To extrapolate the missing data at surface and bottom the 1/6 power law was applied. The instantaneous measurements (i.e. real and extrapolated at $8 \mathrm{~m}$ intervals) were then integrated through the water column to obtain depth-averaged velocity and direction values to be compared with the model output.

Calibration tests were performed to match modelled and measured water levels using the tidal observation stations inside each domain by altering grid properties (e.g., number of cells and grid refinement), boundary conditions (e.g., type and number of boundaries and reflection parameter alpha), physical parameters (e.g., roughness and

292 horizontal eddy viscosity), and numerical parameters (e.g., smoothing time). Of all the parameters analysed, the velocity field is most sensitive to the input model roughness. As in hydraulic engineering, Delft3D uses a resistance coefficient (e.g., Chezy's 
295 Coefficient $C$ or Manning's $n$ ) as input for bottom roughness. For example, when 296 Chezy's or Manning's laws are written in a form applicable to the sea, they are related 297 mathematically to the bed properties [19]:

$298 \quad C \approx\left[\frac{g}{\alpha\left(\frac{z_{0}}{h}\right)^{\beta}}\right]^{0.5}=\frac{g n^{2}}{h^{1 / 3}}$

299 where: $h$ is the water depth; $g$ is the acceleration due to gravity; $\alpha$ and $\beta$ are constants 300 [19]; and $z_{0}$ is the bed roughness length, which in rough hydrodynamic flow is $\sim d_{50} /$ 30112 , with $d_{50}$ being the grain-size diameter. From observations made by diving transects 302 performed when installing the seabed umbilical apparatus and power export 303 infrastructure to shore, the Sanda Sound bottom properties were found to include gravel, 304 sand, mud, and shells. These bottom characteristics are in accordance with the 305 information provided on Admiralty Chart No. 2126 (e.g., G.S.M.Sh). The mean values 306 of $z_{0}$ for a bottom with these sediment types is $\sim 0.3 \mathrm{~mm}$ [19], which corresponds to a 307 value of $C$ of $90-100 \mathrm{~m}^{0.5} / \mathrm{s}$ for deployment depths of 20-25 m (the E35 deployment 308 depth).

309

\subsection{Modelling tidal energy arrays}

311 It is not yet computationally feasible to construct a numerical model capable of 312 resolving the sub-turbine-scale turbulence $(\sim 0.01 \mathrm{~m})$ that is generated as a turbine turns and of incorporating the $20-500 \mathrm{~km}$ of the coastal ocean around the site needed to model tidal patterns in the region [8]. In investigations of coastal hydrodynamics, the grid resolution tends to be low compared with the gradients of the water level, of the velocity, and of the bathymetry (i.e., the hydrostatic pressure assumption may locally be invalid). The incorporation of turbines into coastal models concerns mainly how the drag forces associated with power extraction are modelled [8, 20]. The presence of obstacles in the flow may generate sudden transitions from flow contraction to flow expansion. The forces due to obstacles in the flow that are not resolved (sub-grid) on the horizontal grid need to be parameterized. The energy extraction $\left(P_{e x}, \mathrm{Js}^{-1}\right)$ can be simulated, in principle, by applying an extraction-related retarding force on the flow $\left(U_{I n}, \mathrm{~ms}^{-1}\right)$ using an actuator disc, which can be considered as the effective swept area of a device, perpendicular to the undisturbed fluid flow:

$325 \quad F_{X}=-\frac{P_{e x}}{U_{I n}}$ 
where $F_{X}(\mathrm{~N})$ is the retarding force on the fluid as it passes through the disc. This equation does not include the influence of fluid blockage that the technology may also apply to the fluid [21]. The value of $F_{X}$ (Eq. 6) is normally derived from the most established model for axial force on bodies generating axial resistance (such as a rotor) in oscillatory flow, namely, Morison's (1950) equation [22]. The Morison equation is the sum of two force components: a drag force $\left(F_{D}\right)$ proportional to the square of the instantaneous flow velocity and an inertia force $\left(F_{I}\right)$ in phase with the local flow acceleration:

$F_{X}(t)=F_{D}+F_{I}=\frac{1}{2} \rho U_{i n}(t)\left|U_{i n}(t)\right| A_{T} C_{D}+\rho \dot{u}_{i n}(t) V_{T} C_{M}$

where: $A_{T}$ is the swept area $\left(\pi D^{2} / 4\right) ; V_{T}$ is the volume of the circumscribing sphere (assuming disc-like bodies such as a rotor) $\left(\pi D^{3} / 6\right) ; U_{\text {in }}$ and $\dot{u}_{\text {in }}$ are the flow velocity and acceleration, respectively; $\rho$ is the fluid density; and $C_{D}$ and $C_{M}$ are two empirical hydrodynamic coefficients, the drag and inertia coefficients, respectively, given by:

$C_{M}=\frac{6<F_{X} \dot{u}_{i n}>}{\rho \pi D^{3}<\dot{u}_{i n} \dot{u}_{i n}>}$

$C_{D}=\frac{8<F_{X} U_{I n}>}{\rho \pi D^{2}<U_{I n} U_{I n}\left|U_{I n}\right|>}$

In Delft3D-Flow, obstacles in the flow are denoted as hydraulic structures [17]. These hydraulic structures should be located at velocity points of the staggered grid. To model the force on the flow generated by a hydraulic structure, the flow in a computational layer is blocked. Because a hydraulic structure generates a loss of energy besides that caused by bottom friction, an additional force term is added to the momentum equation to parameterize the extra loss of energy. With respect to Froude's actuator disc theory, a porous plate is used by Delft3D as the hydraulic structure for representing a turbine, that is, a partially transparent structure that extends to the flow along one of the grid directions. Details on modelling tidal energy extraction in coastal models using the actuator disc theory are given by Draper et al. [23].

The principle differences between using porous plates and actual TECs are as follows: (1) the momentum is extracted from the flow and not converted into mechanical motion of the rotor; (2) vortices shed from the edge of the plate differ from those caused by the blades of the TECs; and (3) the swirl angle of the flow from the porous plate is zero [20]. These effects are exclusive to the far wake, and the modelling of TECs in Delft3D focuses on the far-wake effects of the TECs [24]. Thus, it can be assumed that the far 
357

wake is influenced only by the thrust, the diameter of the TECs, the ambient turbulence, and, to a lesser extent, the turbine-generated turbulence.

When the turbine rotor extracts power from the fluid (Eq. 6) this manifests as a pressure drop and a lower fluid velocity behind the rotor plane (Fig. 4A), which in turn manifests as a thrust force, $F_{X}$. Owing to the pressure drop, momentum is extracted. The pressure is assumed to be uniform over the area of the disc. The pressure drop is followed by a decay of the velocity downstream of the disc. Consequently, the control volume expands to satisfy the conservation of mass, that is, the loss of momentum induces a wake. The wake can greatly influence the efficiency of a TEC positioned in the wake of another TEC, for example, in tidal arrays.

7 $\sqrt{10}$ 
377

378

379

380

381

382

383

384

385

386

387

388

389

390

391

392

393

394

395

396

397

398

399

400

401

402

403

$404-\frac{\rho \frac{N}{2}\left(A_{S} C_{S}+A_{T} C_{T 1}\right) U_{I n}{ }^{2}}{\rho \Delta \mathrm{x} \Delta \mathrm{yH}}=-C_{\text {loss }} \frac{U_{I n}{ }^{2}}{\Delta x}$

$C_{D, \text { total }}=\frac{N}{2 A_{c}}\left(A_{S} C_{S}+A_{T} C_{T 1}\right)$ expressed as a quadratic drag law of the form: force and the mass of one Delft3D grid cell:

$M_{\xi}$ has the form of an acceleration term $\left(\mathrm{ms}^{-2}\right)$, where $C_{\text {loss }}$ is the quadratic friction coefficient and input term in the model, $U_{I n}$ is the velocity in the $\xi$ (or x) direction, and $\Delta x$ is the cell width in the $\mathrm{x}$ direction (held at the v-point of cell $M, N$ ). During the simulation, it is assumed that the hydraulic structure is a "sub-grid" and that there is a local equilibrium between the force and the flow due to the obstruction (i.e., generated by the turbine) and the local water-level gradient.

The drag force $\left(F_{D}\right)$ in the direction of the fluid is the thrust $(T)$, namely, a mechanical force generated by the contact of and interaction between a solid object and any fluid (derived from Eq. 7). Conceptually, for a simple array of identical turbines, the total drag force of $\mathrm{N}$ turbines $\left(C_{D, \text { total }}\right)$ can be split into two parts, one due to supportstructure drag and another due to power extraction [8]:

where: $N$ is the total number of turbines; $C_{T 1}$ is one turbine's thrust coefficient based on the area swept by the blades $A_{T} ; C_{S}$ is the gross drag coefficient of the structure supporting one turbine, for example, the fairing and mooring lines, based on their frontal area $A_{s}$; and $A_{c}$ is the channel cross-sectional area. It is important to consider the drag from the supporting structure of the turbine, because this drag can make a significant contribution to the energy removed from the flow [8, 25]. Thus, the total drag force on the fluid $\left(F_{D, \text { total }}\right)$ due to power extraction by an array is typically

$$
F_{D, \text { total }}=\rho C_{D, \text { total }} A_{c} U_{\text {in }}{ }^{2}=\rho \frac{N}{2}\left(A_{S} C_{S}+A_{T} C_{T 1}\right) U_{I n}{ }^{2}
$$

The momentum loss term $\left(M_{\xi}\right)$ can be written as a relationship between the total drag 
405

406

407

where $\mathrm{H}$ is the cell depth and $\Delta \mathrm{y}$ is the cell size in the y direction (perpendicular to the flow, in rectilinear grids $\Delta \mathrm{y}=\Delta \mathrm{x}$ ), which results in a relationship for determining $C_{\text {loss }}$ :

$C_{\text {loss }}=\frac{N\left(A_{S} C_{S}+A_{T} C_{T 1}\right)}{2 \Delta \mathrm{yH}}$

In channels with complex bathymetry, the free-stream flow may differ for each turbine. For the purpose of simplification, here all the turbines are assumed to experience the same free-stream flow and to have the same drag coefficient. Thus, the force on one turbine and the power produced by one turbine in an array can be expressed as [8]:

$F_{1}=\frac{\rho}{2}\left(A_{s} C_{S}+A_{T} C_{T 1}\right)\left|U_{I n}\right| U_{I n}$

$P_{1}=\frac{\rho}{2}\left(C_{P 1} A_{T}\right)\left|U_{I n}\right|^{3}$

where $C_{T 1}$ is the thrust coefficient of a single turbine and $C_{P 1}$ is the power coefficient.

After determining the above values, the user can adjust the model by (1) manipulating the aggregated drag coefficient of the array, $C_{D, t o t a l}$ (Eq. 12), or (2) by manipulating the individual drag coefficient of the turbine, $C_{T 1}$. The value of $C_{T 1}$ can be estimated using the efficiency curve for a generic tidal turbine and the properties of prototypes (Fig. 5; Table 1). The $P_{e x}-U_{\text {in }}$ E35 curve (Fig. 5) as well as values of $C_{D}$ were obtained from OceanFlow Energy, and are based on scaling test values obtained from the wind-wavecurrent tank at Newcastle University using a 1:40 scale model and tests performed at Strangford Narrow using a 1:10 scale model. Both series of tests measured power output, shaft speed, torque, and the drag experienced by the device under the influence of variables such as inflow velocity, operating depth, wave period and amplitude, pitch/yaw angles of the turbine, and blade pitch angle.

The E35 is linked to a control unit onshore. As waves build up in height the instantaneous flow speed as a wave crest passes the rotor will exceed the rated flow speed which is nominally $2.3 \mathrm{~m} / \mathrm{s}$. When the device sees around $2.5 \mathrm{~ms}^{-1}$ the generator is at its maximum overload rated output (i.e. $52.5 \mathrm{~kW}$ ) and is operating at or close to the peak $C_{p}$ value. When the control system detects that the flow is exceeding $2.5 \mathrm{~ms}^{-1}$ it increases the load on the generator until the rotor is working at a lower tip speed ratio and moves into the stall regime. The rotor is less efficient when working in the stall regime so there is an immediate drop off in power output (see Fig. 5). If the waves continue to get larger then as the peak velocity increases with wave height the instantaneous power output continuous to rise. When the control system logs that the 
rotor is already operating in the stall regime and that the power is consistently exceeding the maximum instantaneous output of around $50 \mathrm{~kW}$ then it will shut down the turbine by applying the brake and only allow the brake to be released when the sampled peak flow speed consistently falls below $3.0 \mathrm{~ms}^{-1}$.

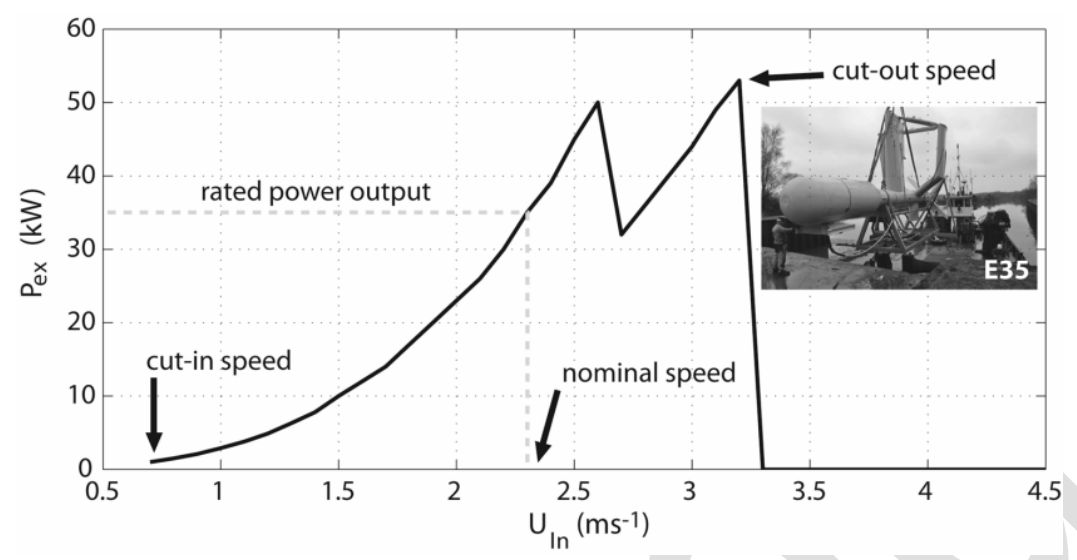

Figure 5. Power curve of the E35 Evopod for the 1:4 scale model deployed at Sanda Sound, South Kintyre (Argyll, Scotland).

The total drag of the model was measured via load cells, and the thrust (from the rotor spinning) was estimated by subtracting the other Eyopod drag components (e.g., mooring lines, the presence of the supporting structure of the rotor itself) from the total drag. The robustness of the physical tank results was confirmed by comparing them with theoretical values computed using the blade element momentum (BEM) theory $[26,27]$. As the grid spacing is dependent on the bathymetric data available (i.e., $250 \mathrm{~m}$ resolution), the "distributed-drag approach" [8] was used by enhancing the natural bottom drag coefficient, $C_{D, \text { total }}$, over the area spanned by the array. The model uses a "sigma" coordinate system, which means that the thickness of the vertical layers changes as the water level rises and falls according to tidal movements. The position of a porous plate is specified in terms of these layers. Because the porous plates are represented in grid cells of $\sim 20-25 \mathrm{~m}$ depth, the first sigma layer is $33.3 \%$ of the total depth (i.e., the first $\sim 7 \mathrm{~m}$ of the water column). For a floating turbine with a rotor diameter of $4.5 \mathrm{~m}$, the extraction always occurs between the water line and a depth of $\sim 7 \mathrm{~m}$, independently of the rise and fall of the water column as the tide ebbs and floods. Since an area of $50 \mathrm{~m} \times 50 \mathrm{~m}$ is required for the moorings of each E35 device, each cell can fit approximately five turbines, and $C_{D, \text { total }}$ and $C_{\text {loss }}$ were determined using 
462 Equations 12 and 15, respectively (Table 4). The power available at each grid cell is 463 directly related to the inflow velocity to which the turbine is exposed. The rotor

473 For the particular case of the E35 device, the influence of the rotor occupies $\sim 33 \%$ of 474 the water column. Assuming that the turbines are oriented cross-flow, the inflow 475 velocity is one-third of the cross-flow component at the depth outputted from the 476 Delft3D (i.e., the first sigma cell). Thus, five turbines each with a diameter of $4.5 \mathrm{~m}$ 477 occupying a grid cell of $250 \mathrm{~m}$ means that the total area occupied by E35 devices is $\sim 10 \%$ of the grid cell size. The potential extractable kinetic power produced by a single E35 device is given by:

$P_{E 35}=\frac{1}{2} \rho C_{p} A_{T} U_{\text {In }}^{3}$

481 where $C_{p}$ is the power coefficient, that is, the effectiveness of a turbine at a specific 482 flow velocity. For simplicity, and according to the flume tests, $C_{p} \sim 0.33$ for the E35. A 483

Table 4. Drag force $\left(F_{d}\right)$ and array drag coefficient $\left(C_{D, \text { total }}\right)$ values based on the Evopod E35 $U_{I n}-P_{e x}$ curve and characteristics. Array drag coefficient values were determined considering a grid cell size of $250 \mathrm{~m}$, five turbines per cell (all operating at nominal velocity), and a cell depth $(H)$ of $\sim 20 \mathrm{~m}$.

\begin{tabular}{clc}
\hline Parameter & \multicolumn{1}{c}{ Description } & Value \\
\hline $\boldsymbol{D}$ & Diameter of the rotor $(\mathrm{m})$ & 4.5 \\
$\boldsymbol{A}_{\boldsymbol{s}}$ & TEC frontal area $\left(\mathrm{m}^{2}\right)$ & 20.3 \\
$\boldsymbol{A}_{\boldsymbol{T}}$ & Rotor swept area $\left(\mathrm{m}^{2}\right)$ & 16 \\
$\boldsymbol{C}_{\boldsymbol{s}}$ & Gross drag coefficient of the structure & 0.19 \\
$\boldsymbol{C}_{\boldsymbol{T}}$ & Thrust coefficient & 0.71 \\
$\boldsymbol{L}$ & TEC length $(\mathrm{m})$ & 13 \\
$\boldsymbol{B}$ & TEC beam $(\mathrm{m})$ & 4.5 \\
$\boldsymbol{V}_{\boldsymbol{T}}$ & Volume of the circumscribing sphere $\left(\mathrm{m}^{3}\right)$ & 47.7 \\
$\boldsymbol{U}_{\boldsymbol{I} \boldsymbol{n}}$ & Nominal speed $\left(\mathrm{ms}^{-1}\right)$ & 2.3 \\
$\boldsymbol{d}$ & Depth of the cell $(\mathrm{m})$ & 20 \\
$\boldsymbol{F}_{\boldsymbol{d}}$ & Drag force at nominal speed $(\mathrm{N})$ & 30435 \\
$\boldsymbol{C}_{\boldsymbol{D}, \text { total }}$ & Array drag coefficient & 0.012 \\
\hline
\end{tabular}
depiction of the layout is given in Figure 6. 
484 The device capacity factor is the ratio of the actual energy produced per annum divided by the potential energy produced if the device was working continuously at its rated output. The potential energy recovered over a year is given by:

$E_{\text {Annual }}=\frac{1}{2} \rho C_{p} A_{T} U_{\max }{ }^{3} \frac{4}{3 \pi} T$

488

489

where $T$ is the annual period and $U_{\max }$ is the nominal velocity. Therefore the energy produced by a device in sinusoidal flow is only $\frac{4}{3 \pi}$ or 0.424 times that produced in a steady current of the same maximum speed [28].
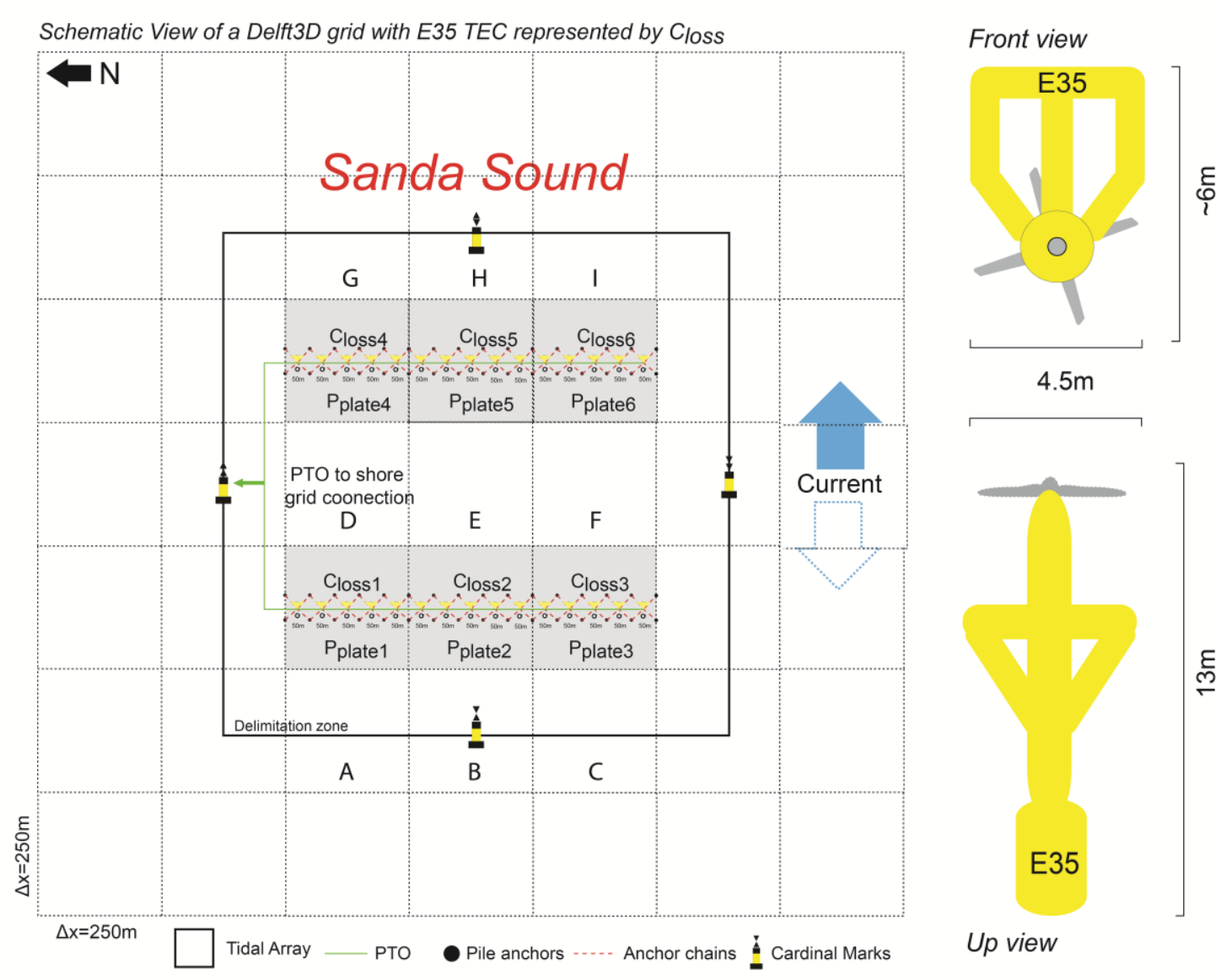

Up view

Figure 6. Sketch of the layout of the Evopod E35 turbines at Sanda Sound with power take-off (PTO) to shore. Turbines are represented as porous plates at several grid cells of $250 \mathrm{~m} \times 250 \mathrm{~m}$ in the Delft 3D hydrodynamic model. The grid area represents a location inside the white box of Figure 3A. The grey grid cells are blocked to simulate the extraction of energy by the momentum loss term $\left(C_{\text {loss }}\right)$. Velocity deficit and water-level differences are assessed in grid cells up current and down current of the porous plates (i.e., cells ABC, DEF, and GHI).

The reference situation is the model run without turbines. The two analysed scenarios are: (S1) the placement of a row of 15 turbines (Pplates 1-3) from $\mathrm{N}$ to $\mathrm{S}$ occupying 
502

503

504

505

506

507

508

509

510

511

512

513

514

515

516

517

518

519

520

521

522

523

524

525

526

527

528

529

530

531

532

$750 \mathrm{~m}$ of the channel area between cells ABC and cells DEF; and (S2) the placement of two rows with a total of 30 turbines, 15 from $\mathrm{N}$ to $\mathrm{S}$ occupying $750 \mathrm{~m}$ of the channel area between cells ABC and cells DEF, and the other 15 (Pplates 4-6) from $\mathrm{N}$ to $\mathrm{S}$ occupying another $750 \mathrm{~m}$ of the channel area between cells DEF and cells GHI (Fig. 6). One-month model runs were used to assess the energy production and hydrodynamic impact of the tidal array by simulating both the momentum extraction and the induced far-wake effect of each array scheme, comparing the velocity field with and without the inclusion of porous plates for point locations (i.e., cells $\mathrm{ABC}$, DEF, and GHI), immediately upward and downward of the array scheme.

The velocity deficit $\left(U_{D}\right)$ is determined by:

$U_{D}=\left(\frac{U_{I n}-U_{T}}{U_{I n}}\right)$

where $U_{T}$ is the velocity at the cell with turbines represented as porous plates. Differences in water elevation $\left(W L_{D}\right)$ were determined for each cell (A-G, Fig. 6) by subtracting the water elevation output from the no-extraction scenario. By including the porous plates as an analogy to the disc theory, a pressure drop is formed close to the porous plate. This pressure drop manifests as a thrust force $\left(F_{D, \text { total }}\right)$, and momentum is extracted $\left(M_{\xi}\right)$. The pressure is assumed to be uniform over the area of the porous plate. The pressure drop is followed by a decay of the velocity downstream of the disc $\left(U_{D}\right)$. Consequently, the control volume expands to satisfy the conservation of mass. The $C_{D, \text { total }}$ is dependent on the operational conditions, which means that $C_{\text {loss }}$ should be modified by considering the inflow velocity at the entry of the rotor. This is not yet possible using coastal models such as Delft3D, and therefore simulations must be performed using a constant coefficient.

\section{Results}

\subsection{Model Validation}

A comparison between measured and modelled water levels was performed for four sites located in the Irish Sea covering the spring and neap periods (Fig. 7). For site 1 (Aberdyfi, circle 1 in Fig. 3A), located on the eastern coast of Ireland and close to the model boundary, the agreement is good $\left(r^{2}=0.96\right.$, RMSE $\left.=0.20 \mathrm{~m}\right)$. The model performs slight better during high tide, under predicting the peak water levels at low 
533 tide, especially during spring tides (Fig. 7A). For sites 2 (Bally Castle Bay, Northern

534 Ireland) and 3 (Troon, west coast of Scotland) (circles 2 and 3 in Fig. 3A, respectively),

535 which are closer than site 1 to the Kintyre Peninsula, the agreement is very good $\left(\mathrm{r}^{2}=\right.$ $5360.99, \operatorname{RMSE}=0.01 \mathrm{~m}$ ) during the spring-neap cycle (Fig. 7B-C). Finally, for site 4 537 (Campbeltown, located north of Sanda Sound on the Kintyre Peninsula) (circle 4 in 538 Fig. 3), the agreement between modelled values and the IHO tidal station values is 539 overall very good $\left(\mathrm{r}^{2}=0.99\right.$, RMSE $\left.=0.01 \mathrm{~m}\right)$, particularly considering that site 4 540 belongs to both the coarse- and medium-resolution models.
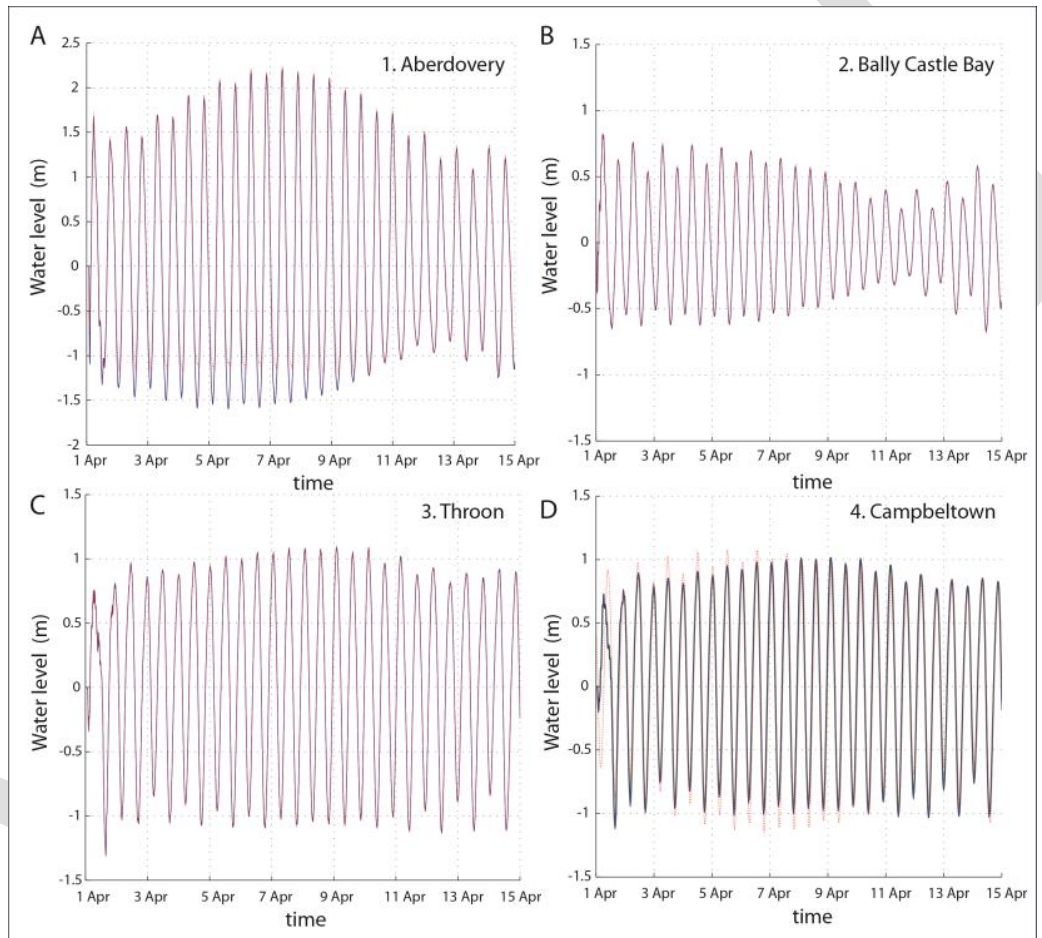

543

Figure 7. Modelled and IHO observed water levels at (A) Aberdyfi, Wales; (B) Bally Castle Bay, Northern Ireland; (C) Troon, Scotland; (D) Campbeltown, South Kintyre, Scotland.

A comparison between measured and modelled depth-averaged current speeds and current directions was performed for the POL ADCP site (see location in Fig. 3). In general, the agreement is very good: $\mathrm{r}^{2}=0.83, \mathrm{RMSE}=0.09 \mathrm{~ms}^{-1}$ for the current speed; and $r^{2}=0.84, \operatorname{RMSE}=30^{\circ}$ for the current direction (Fig. 8). Overall, the coarseresolution model is able to reproduce the water level, current speed, and current direction observed at the IHO tidal stations and those obtained using ADCP 
552 measurements. The coarse-resolution model can therefore be used with confidence to generate the boundary conditions for the medium-resolution model.
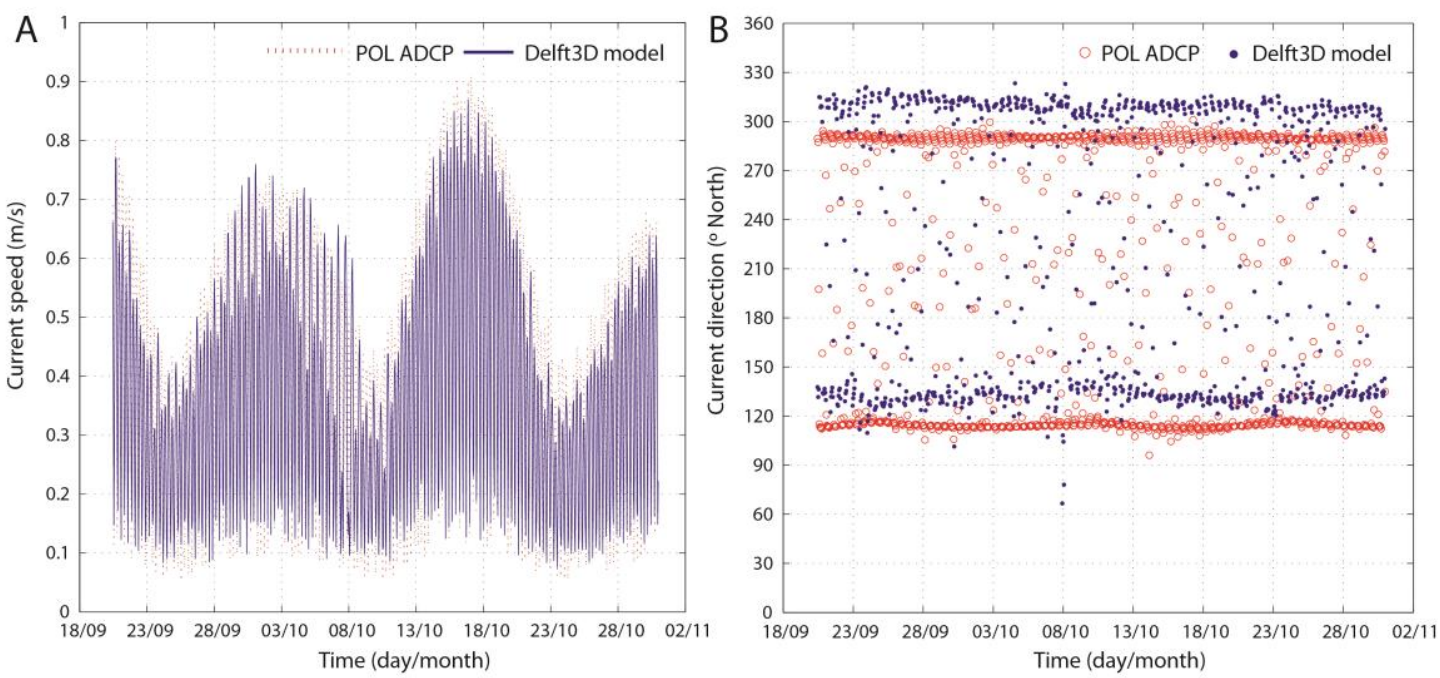

Figure 8. Modelled and measured (A) current speed and (B) current direction at a point south of Kintyre Peninsula in the Irish Sea $\left(54^{\circ} 59.83 \mathrm{~N}, 05^{\circ} 29.96 \mathrm{~W}\right.$, water depth $\left.139 \mathrm{~m}\right)$.

\subsection{Energy extraction simulations}

The modelled cross-rotor flow for the top third of the water column during the peak ebb of spring tides is shown in Figure 9A, and the cross-rotor flow velocity magnitude and potential extractable power for a single E35 device are displayed in Figure 9B and C, respectively. Assuming a constant $C_{p}$ in Equation 18, and taking into account the porous plate locations (see Fig. 6), the potential extractable power of five turbines for a grid cell was modelled and is shown in Figure 10. Each plot in Figure 10 shows the annual power output in MWh, obtained by integrating the hourly results of extractable kinetic power throughout the analysed month and then multiplying by 12 months. For a total of 30 E35 turbines (with a total installed capacity of $\sim 1 \mathrm{MW}$ ), the total power output is $\sim 1500$ MWh (five E35 devices per cell), with values ranging between 168 and $303 \mathrm{MWh}$. The range in power output values clearly reflects the importance of choosing the location of the array, as slight changes in the location (of $<1 \mathrm{~km}$ ) can approximately double the potential power output. 

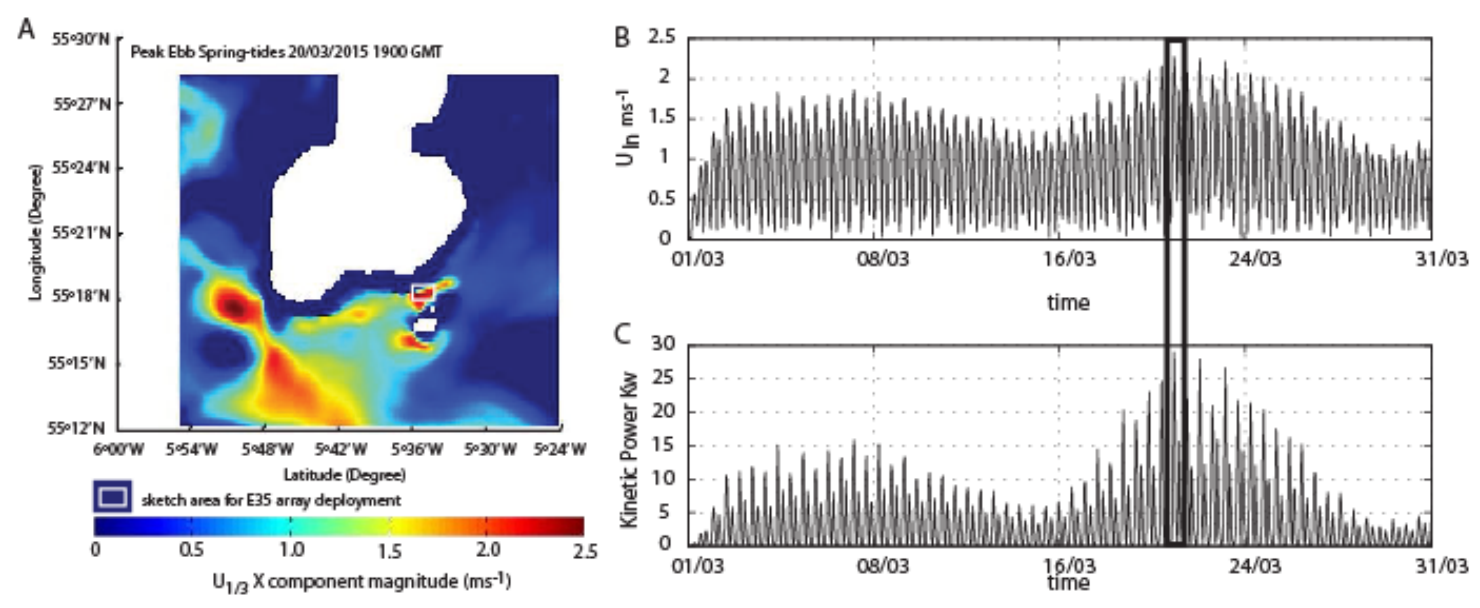

Figure 9. (A) Modelled cross-rotor flow for the top third of the water column during peak ebb of spring tides, showing the area of interest around the location of the currently deployed E35 device (white box); (B) representative flow velocities for a grid cell inside the area of interest $\left(U_{I n}\right)$; (C) potential extractable power for a single E35 device for a representative month. The black box marks the maximum potential kinetic power extracted by a single device at peak flow (spring tides, $\sim 30 \mathrm{~kW}$ ).
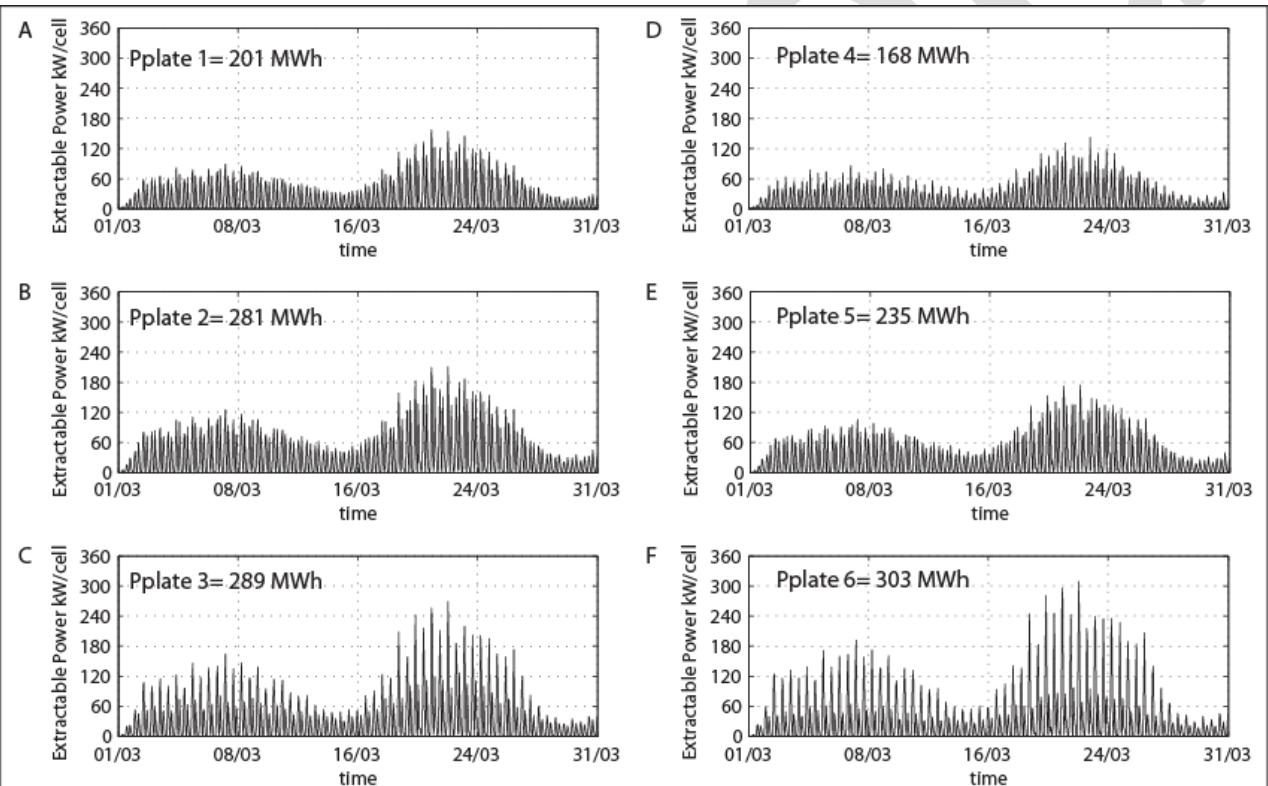

Figure 10. (A-F) Extractable power (kW/cell) and annual power output estimates (MWh) for each grid node location represented by a $250 \mathrm{~m} \times 250 \mathrm{~m}$ cell size in which five E35 devices are hypothetically placed, extracting power in the top third of the water column ( $20 \mathrm{~m}$ depth), and assuming a constant power coefficient $\left(C_{p}\right)$ and uniform flow $\left(U_{I n}\right)$.

The effect of the turbines was then included as a loss in the momentum equations according to the above scenarios (as represented in Fig. 6) and by choosing an area within the model where cell depths were $\sim 20-25 \mathrm{~m}$. The results for velocity deficit $\left(U_{D}\right)$ and water-level differences $\left(W L_{D}\right)$ for scenarios S1 and S2 are shown in Figs. 11 and

591 12, respectively. For S1, and for one-month simulations, the mean values of $U_{D}$ varied 592 from $\sim 0.035 \mathrm{~ms}^{-1}$ (Cells A and D), to $\sim 0.02 \mathrm{~ms}^{-1}$ (Cells B and E), and to $\sim 0.03 \mathrm{~ms}^{-1}$ 
593 (Cells $\mathrm{C}$ and F). Maximum flow alterations ranging from 0.07 up to $0.16 \mathrm{~ms}^{-1}$ were 594 registered. For water-level differences, the mean $W L_{D}$ ranged between 1.6 and $2.0 \mathrm{~mm}$ with maximums of $\sim 8.5-11.0 \mathrm{~mm}$.
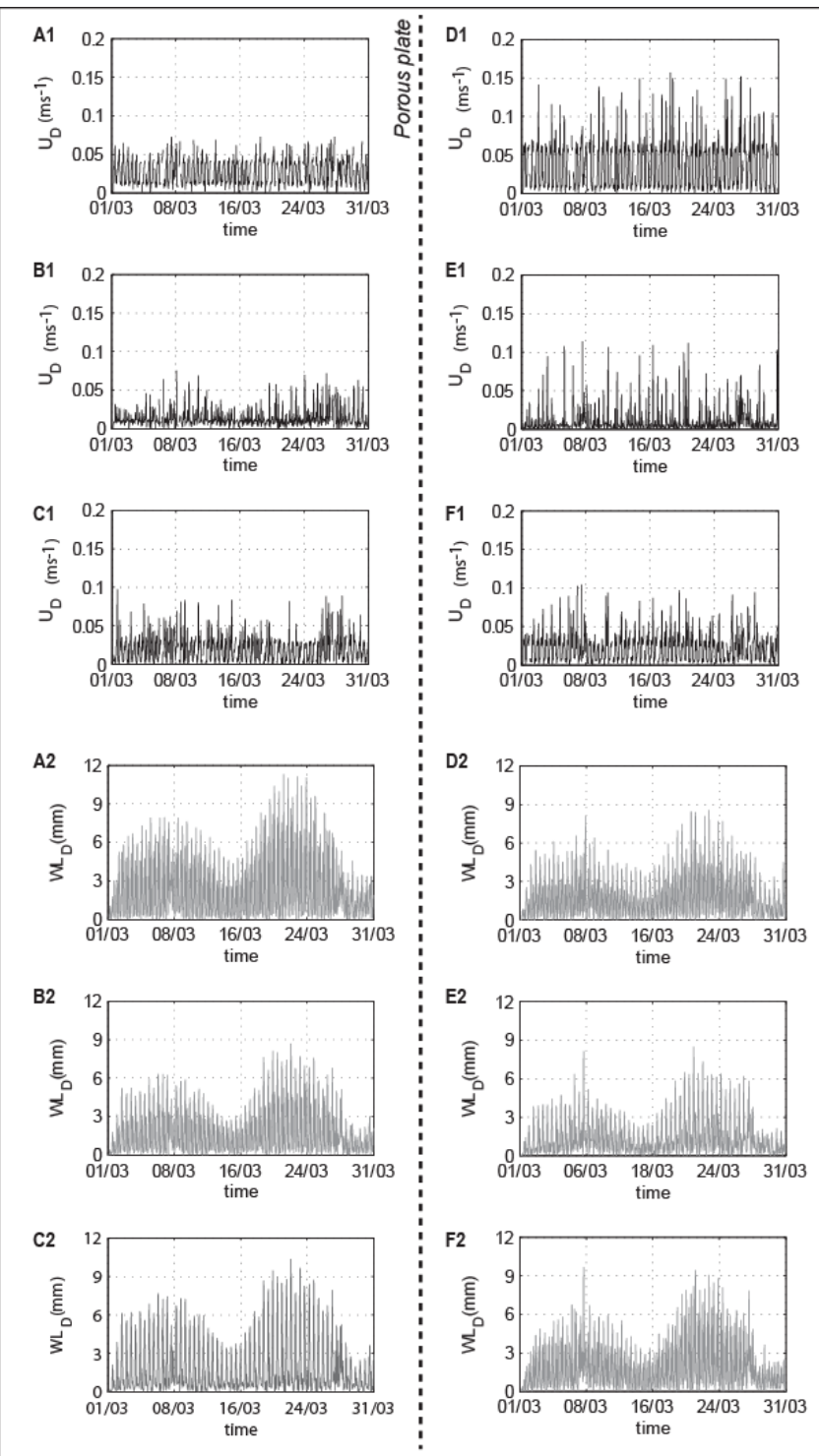

Figure 11. (A-F) Estimated velocity deficit $\left(U_{D}, \mathrm{~A} 1-\mathrm{F} 1\right)$ and water-level differences $\left(W L_{D}, \mathrm{~A} 2-\mathrm{F} 2\right)$

Adding more turbines to the model directly increases the values of both $U_{D}$ and $W L_{D}$ cells DEF, Fig. 6). The mean $U_{D}$ is $\sim 0.1 \mathrm{~ms}^{-1}$ for cells A, D, and G, $\sim 0.07 \mathrm{~ms}^{-1}$ for cells 
$607 \mathrm{~B}, \mathrm{E}$, and $\mathrm{H}$, and $\sim 0.08 \mathrm{~ms}^{-1}$ for cells $\mathrm{C}, \mathrm{F}$, and I. However, the maximum flow

608

609

610

611

612

613

614

615

616

alterations have a greater influence on velocity deficit, with values of $0.30,0.35$, and $0.30 \mathrm{~ms}^{-1}$ (cells A, D, and G, respectively), 0.25, 0.42, and $0.38 \mathrm{~ms}^{-1}$ (cells B, E, and $\mathrm{H}$, respectively), and 0.2, 0.4, and $0.5 \mathrm{~ms}^{-1}$ (cells $\mathrm{C}, \mathrm{F}$, and $\mathrm{G}$, respectively). With respect to water-level differences, the mean $W L_{D}$ ranges between 2.1 and $5.1 \mathrm{~mm}$ with maximums of $\sim 13-26 \mathrm{~mm}$. These results show that doubling the installed capacity has the effect of approximately doubling the mean velocity deficit and water-level differences and of increasing by a factor of 4 the registered maximum values of $U_{D}$ and $W L_{D}$, mainly during spring tides.
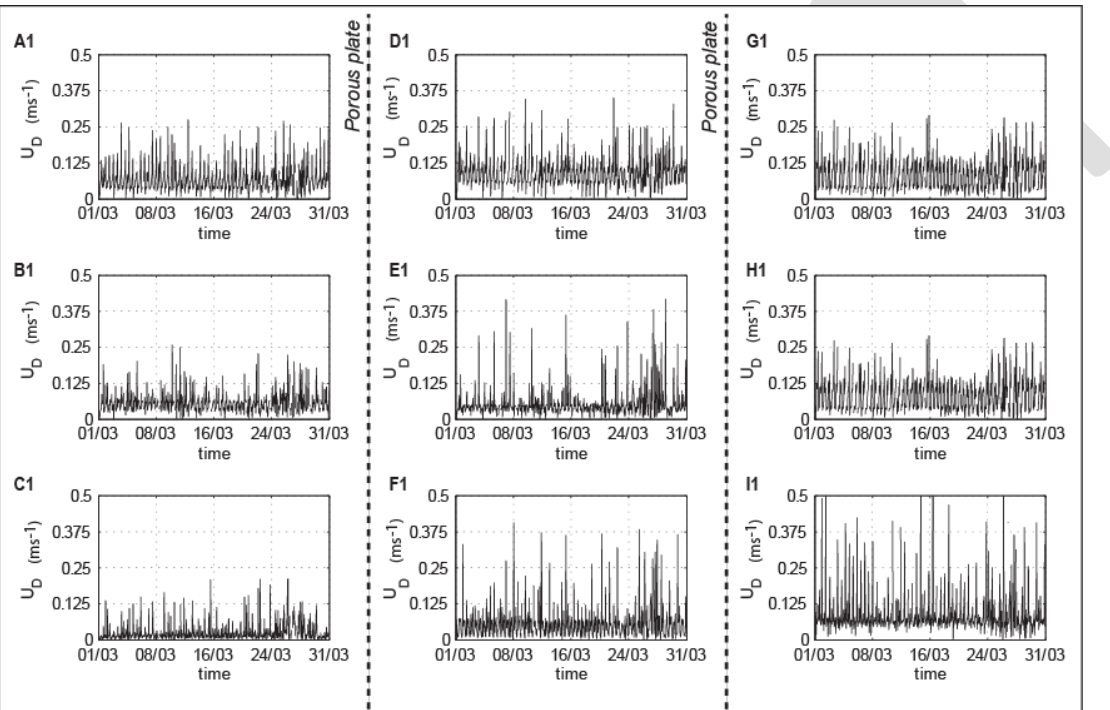

11
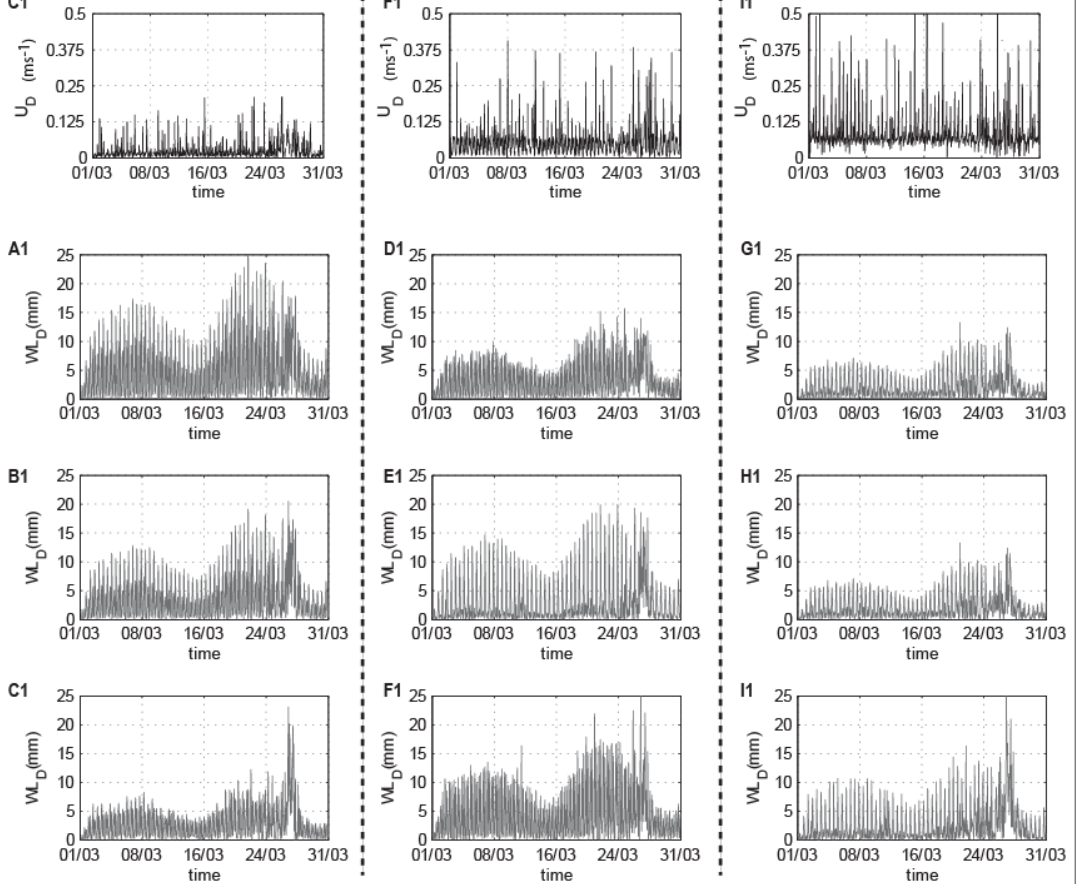

Figure 12. (A-I) Estimated velocity deficit $\left(U_{D}, \mathrm{~A} 1-\mathrm{I} 1\right)$ and water-level differences $\left(W L_{D}, \mathrm{~A} 2-\mathrm{I} 2\right)$ 


\subsection{Capacity Factor of a small array}

Based on the modelling simulations annual power output estimates (MWh) for each grid node location were determined (Fig. 11) considering the placement of five E35 devices for node on a total of 30 turbines. Considering the nominal velocity on Eq.19 and if a tidal variation is assumed to be sinusoidal then the theoretical capacity factor is the area under the sinusoid is 0.424 times the peak output (power output at peak flow speed). Likewise, if a neap tide is half the speed of a spring tide then the theoretical capacity factor over a lunar month drops to 0.212 times the peak output. Other capacity factors can be determined e.g. if the $2^{\text {nd }}$ tide is only $80 \%$ of the first tide, which is not uncommon, then the theoretical capacity factor drops further to 0.17 . However by rating the turbine to give its peak output at less than the maximum spring tide flow speed it is possible to push up the capacity factor and a value of 0.30 is reasonable. Based on the results obtained by the model simulations, Table 5 presents the capacity factors calculated for each of the grid nodes.

Table 5. Summary of the capacity factors and total annual output (MWh) based on the simulations performed for a small array of floatable E35 devices placed at Sanda Sound.

\begin{tabular}{lcccccc}
\hline Parameter & Pplate1 & Pplate2 & Pplate3 & Pplate4 & Pplate5 & Pplate6 \\
\hline Rated output (kW) & 35 & 35 & 35 & 35 & 35 & 35 \\
$\begin{array}{l}\text { Annual power output per turbine } \\
\text { (MWh) }\end{array}$ & 40.2 & 56.2 & 57.8 & 33.6 & 47 & 60.6 \\
Capacity Factor & 0.14 & 0.20 & 0.21 & 0.12 & 0.17 & 0.22 \\
$\begin{array}{l}\text { Number of turbines } \\
\text { Total Installed Capacity (all }\end{array}$ & 5 & 5 & 5 & 5 & 5 & 5 \\
turbines) (kW) & 175 & 175 & 175 & 175 & 175 & 175 \\
$\begin{array}{l}\text { Total Annual Output (all } \\
\text { turbines) (MWh) }\end{array}$ & 201 & 281 & 289 & 168 & 235 & 303 \\
\hline
\end{tabular}

Considering the rated output of E35 $(35 \mathrm{~kW})$ and a capacity factor of 0.3 , and assuming fix other parameters such as $C_{p}(0.33)$, transmission efficiency $(96 \%)$ and availability (95\%), the theoretical annual output for a single turbine is $84 \mathrm{MWh}$ which traduces to a total of $2517 \mathrm{MWh}$ for a small array of 30 E35 turbines (1050kW of installed capacity). Based on the simulations performed within this paper (Fig. 11) the total annual output is of $1477 \mathrm{MWh}$ (Table 5) i.e. 59\% of the theoretical annual output. The location represented by Pplate6 reports the higher capacity factor, which means that if similar locations were found a total of $1818 \mathrm{MWh}$ of annual energy could be produced by a small array of 30 turbines i.e. $72 \%$ of the theoretical annual output, representing an increment of $13 \%$ on energy production in respect to the sketch alignment of Fig. 6. 


\section{Discussion}

652 Hydrodynamic coastal models can be used to incorporate large numbers of turbines 653 using a coarse representation of the devices, such as presented in this paper. These 654 models are required for analysing fluid flows, improving complex simulation scenarios 655 prior to installing TECs, and establishing energy extraction maximum limits without 656 causing significant disturbances to the flow, to the sediment transport patterns, and to 657 channel cross-section stability [7-8, 20, 29-30]. Currently, little is known about the 658 environmental effects of TEC devices. To successfully perform environmental impact 659 studies with respect to such devices, it is essential to understand the local 660 hydrodynamics, namely, how flow varies naturally and how any proposed tidal energy 661 array compares with such natural variability [30-32].

662 The tidal energy industry is reaching commercial status following the testing of different TEC prototypes in recent years. The next logical step for the industry is the installation of multiple devices in arrays. The "distributed-drag approach" used in the present study is able to give a good indication of the potential power that can be extracted by these device arrays. Results from the simulations performed here showed that for the selected location, a 1-MW installed capacity at Sanda Sound Channel with E35 Evopod floatable devices can yield a combined annual power output of $\sim 1500 \mathrm{MWh}$. Using porous plates in locations with high resource potential, and assuming that equivalent locations could be found within or in the vicinity of Sanda Sound, the annual maximum power output for the same installed capacity could reach $>2500 \mathrm{MWh}$ (considering a capacity factor of 0.3 ).

The values for power output calculated in the present study are slightly lower than those obtained from preliminary spectral modelling provided by consultants Aquamarine

675 Power, who calculated a total annual power output of 2500-3100 MWh for a 1-MW tidal array deployed at Sanda Sound [13]. However, as demonstrated in the present study, slight alterations in inflow velocities caused by differences in device location of just $1 \mathrm{~km}$ can double the power output. These results are important since show that small alteration on the flow related to the placement of turbines can change considerably the annual power output. Therefore, resource assessments of power output for a given site using coastal models provide a good preliminary evaluation that should be complemented with detailed ADCP measurements. The use of floatable and smaller devices such as the E35 has obvious advantages, because these devices can be easily 
684 detached from their moorings and repositioned in other more energetic locations, 685 thereby optimising the layout of a tidal energy array. Since the cost of hydrokinetic 686 electricity is still one of the major disadvantages of TEC development at large scales, 687 the use of validated hydrodynamic model and it output results are an important tool for 688 the development of tidal stream energy projects in order to: (1) design realistic tidal 689 array configurations and model the flexibility of the mooring and power export cabling 690 systems for these arrays, (2) evaluate alternative mooring solutions involving tension 691 tethers and pin-pile anchors to allow closer spacing of turbines and improved array scheme economics by permitting replacement of devices, (3) propose electrical connection and isolation strategies for the interconnected array and the export of that power back to shore, and (4) supply data for performing cost benefit analysis of different extractions scenarios.

The power extraction from any tidal flow will alter both the near-field and far-field flow patterns. This study estimated the effects of energy extraction on the circulation patterns at a particular location by positioning operational TEC devices in the model domain. To simulate the force on the fluid due to power extraction by a single TEC or an array of such devices, the quadratic drag law was used by adding a momentum sink in the governing momentum equations. The effects of energy extraction were analysed by examining changes in water levels and in velocity field patterns occurring as a consequence of energy extraction. The momentum sink represented the pressure drop across the TEC rotor and allowed energy extraction from the free flow to be simulated. Results of the simulations performed using two different extraction scenarios represented by porous plates showed that doubling the installed capacity (i.e., doubling the number of TEC devices) has the effect of doubling both the mean velocity deficit and water-level differences in the area surrounding the extraction point. These differences in the velocity deficit and in water levels can be amplified by a maximum factor of 4 during the peak flood/ebb of spring tides.

711 In a similar study, the removal of $10 \%-60 \%$ of kinetic power from a cross-section of 712 the Beaufort River (South Carolina, USA) was simulated (by applying the momentum 713 sink approach) using a 3D model with 200-m grid cells by enhancing the drag coefficient at the extraction site [30]. The results showed that for a $10 \%$ extraction, the flow is diverted laterally from the extraction point with a reduction in the flow speed of $20 \%$ at the extraction site and an increase in the flow speed of $5 \%$ at adjacent locations. 
717 An increase to $60 \%$ of the extraction resulted in a modification of the water levels by up

718 to half a centimetre and some changes in adjacent channels, highlighting that a small

719 (meters) energy extraction device can result in changes in circulation patterns at much

720 larger scales (1-10 km). A study conducted for another estuary, the Ria de Ortigueira

721 (Galicia, Spain), simulated the implementation of a TEC array, also using the

722 momentum sink in a 3D model [7]. The effects of energy extraction on tidal flow were

723 simulated for typical summer and winter regimes, using a value of $C_{P}$ of 0.4 , for an

724 array positioned across a channel section. The results showed that water-level

725 modifications were concentrated in the area occupied by the array. Maximum variations

726 in water level of $8 \mathrm{~cm}$ were recorded, with maximum flow alterations of up to $0.3 \mathrm{~ms}^{-1}$

727 and $0.03 \mathrm{~ms}^{-1}$ in the transient and residual circulations, respectively. The effects on the

728 residual circulation were felt over a wider region, as far as $2 \mathrm{~km}$ away from the

729 extraction point.

730 Although energy extraction can be effectively simulated in coastal models using several

731 parametric approaches, better understanding of the tidal resource and of local bed

732 friction is required. The problem is that to effectively validate the numerical predictions,

733 access to data from real installations is required. However, up until now, there have

734 been very few tidal turbines in use around the world. In the few cases in which devices

735 have been deployed, the monitored data are highly commercially sensitive and not

736 distributed to the public and research community [33-35]. As an example, in situ

737 measurements of turbulence using ADCPs at the European Marine Energy Centre

738 (EMEC) in the Orkney Islands (Scotland) have revealed complex turbulent flow, with

739 the production of turbulent kinetic energy (TKE) being enhanced near the seabed [33,

740 34]. However, the majority of flow field studies around tidal turbines have been

741 conducted in laboratories $[19,36]$.

742 The implementation of a TEC array can modify the absolute current (both near- and far-

743 field) and the intensity and spatial variability of turbulence (near-field). The

744 aforementioned case studies [7, 30] differ from the present case study in that the effect

745 induced by the TECs on the fluid is represented by bed friction, which is applicable

746 only for far-field studies [20]. In the present study, the turbine thrust coefficient is used

747 for calculating the thrust force exerted on the fluid and the coefficient value is specified

748 based on experimental results performed in physical flumes and also on data from

749 testing with scale prototypes. In the simulations, the drag coefficient was however set to 
750 be constant, which actually represents a fixed operational state of the turbine. This is a

751 limitation of these coastal models that cannot presently be solved, and therefore the

752

753

754

755

756

757

758

759

760

761

762

763

764

765

766

767

768

769

770

771

772

773

774

775

776

777 modelling of TECs in Delft3D focuses on the large-scale (far-wake) effects of array schemes. Using a porous plate in analogy with the disc theory assumes that the swirl angle of the flow from the porous disc will be zero. Thus, the far wake is influenced only by the thrust, the diameter of the turbine, the ambient turbulence, and, to a lesser extent, the turbine-generated turbulence $[8,20]$.

Nesting models with different resolutions, as performed in the present study, makes it possible to continuously improve the accuracy of the quantification of momentum loss by representing the turbine characteristics close to the actual scale of the turbine. This is because the accuracy of the nested model ultimately depends on the availability of data (e.g., the resolution of the bathymetry and high-resolution ADCP data), as well as on the use of different modelling set-ups (e.g., curvilinear and unstructured grids with high resolution). For the particular analysed case of a floatable turbine, the next step is to improve the accuracy of the overall drag of the turbine while extracting energy using load cells placed on the mooring lines and by measuring simultaneously the combined wave and flow parameters passing the turbine (e.g., deploying pressure transducers and flow meters both on the turbine structure and in the water column). Implementing a detailed model in the area of interest by creating a sub-nested, finer model would also allow the grid cell size to approach the turbine scale.

\section{Conclusion}

The aim of this study was to implement a momentum sink in a hydrodynamic coastal model based on a real prototype deployment and thereby evaluate the effects of energy extraction on flow patterns. Energy extraction techniques such as that proposed in this paper cannot currently be verified against real-scale measurements, either in terms of resource assessment or for predicting the environmental impacts of energy extraction. Such techniques are however useful for providing the detailed temporal and spatial distributions of tidal energy density accounting for coastal topography, for investigating the interactions between turbine far wakes, and for estimating the potential energy output of tidal current power. The approach used is also effective for comparing extraction scenarios with the benchmark situation (i.e., no extraction). However, the approach does not provide a direct way of connecting power production to the number 
783

784

785

786

787

788

789

790

791

792

793

794

795

796

797

798

799

800

801

802

803

804

805

806

807

808

809

810

811

812

813

814

815

of turbines in an array; therefore, it should not be used to estimate how many turbines are required to realise a given (desired) power output.

A step forward to improve the accuracy with which the velocity of the wake and consequently the interaction of the wakes can be modelled is to accurately represent the extraction of momentum from the flow in coastal models. This can be effectively improved only when measurements from real devices are available for comparison. A feasible solution would be the simultaneous measurement of velocity data both upwards and downwards of the extraction point. This could be achieved in practical terms by measuring the input velocity by deploying a fixed bottom-moored ADCP, and by collecting continuous instantaneous velocity profiles for the wake by operating a vesselmounted ADCP with bottom tracking downwards of the extraction point and along the flow direction. Additionally, and to further quantify the effects of energy extraction on the environment, the nested model has to include a feedback mechanism between the evolving bathymetry and the hydrodynamics i.e. the two nested models can be fully coupled for the automatic transfer of relevant data back and forth to simulate short- and long-term time-dependent changes to hydrodynamics, sediment transport and sea-bed morphology. Ongoing research will further explore the use of these techniques and accurately validate the energy extraction from the flow in order to better represent the effect of energy extraction on hydro-morphodynamic models by using real (full-scale) prototypes extracting energy from the flow.

\section{Acknowledgments}

The work was supported by Wattage (Workability Aspects of Tidal Turbine Arrays on producing Green Energy), a project funded by the OceanERANET Joint Call 2014. The paper is also a contribution to the SCORE project funded entity by the Portuguese Foundation for Science and Technology (FCT - PTDC/AAG-TEC/1710/2014). André Pacheco was supported by the Portuguese Foundation for Science and Technology, under the Portuguese Researchers' Programme 2014 entitled "Exploring new concepts for extracting energy from tides" (IF/00286/2014/CP1234). The work contains data supplied by the Natural Environment Research Council (UK, Series 666134 RD-0394). We acknowledge Graeme Mackie from Ocean Flow Energy for supporting our research efforts on tidal energy and the independent reviewers and editors for contributing to improvements in earlier versions of this work. 


\begin{tabular}{|c|c|c|}
\hline 817 & $\mathrm{ADCP}$ & Acoustic Doppler Current Profiler \\
\hline 818 & $A_{T}$ & Swept area $\left(\mathrm{m}^{2}\right)$ \\
\hline 819 & $A_{S}$ & Device hull area $\left(\mathrm{m}^{2}\right)$ \\
\hline 820 & $A_{C}$ & Cross-sectional area $\left(\mathrm{m}^{2}\right)$ \\
\hline 821 & C & Chezy's resistance coefficient \\
\hline 822 & $C_{D}$ & Drag coefficient of a single turbine \\
\hline 823 & $C_{D, \text { Total }}$ & Drag coefficient of device array \\
\hline 824 & $C_{\text {loss }}$ & Quadratic friction coefficient \\
\hline 825 & $C_{M}$ & Inertia coefficient \\
\hline 826 & $C_{p}$ & Power coefficient \\
\hline 827 & $C_{S}$ & Gross drag coefficient of the structure \\
\hline 828 & $C_{T 1}$ & Thrust coefficient of an individual turbine \\
\hline 829 & $d$ & Depth below reference plane $(\mathrm{m})$ \\
\hline 830 & $D$ & Diameter of the turbine rotor $(\mathrm{m})$ \\
\hline 831 & $d_{50}$ & Mean grain size diameter $(\mathrm{m})$ \\
\hline 832 & $\xi$ & Water level above reference plane (m) \\
\hline 833 & $g$ & Gravitational acceleration $\left(\mathrm{ms}^{-2}\right)$ \\
\hline 834 & $H$ & Depth of the grid cell (m) \\
\hline 835 & $h$ & Water depth (m) \\
\hline 836 & $\rho$ & Water density $\left(\mathrm{kgm}^{-3}\right)$ \\
\hline 837 & $\rho^{\prime}$ & Anomaly density $\left(\mathrm{kgm}^{-3}\right)$ \\
\hline 838 & $\rho_{0}$ & Reference density $\left(\mathrm{kgm}^{-3}\right)$ \\
\hline 839 & $F_{D}$ & Drag force on the fluid by the turbine energy extraction $(\mathrm{N})$ \\
\hline 840 & $F_{D, \text { Total }}$ & Drag force on the fluid by the array energy extraction $(\mathrm{N})$ \\
\hline 841 & $F_{I}$ & Inertia force on the fluid $(\mathrm{N})$ \\
\hline 842 & $F_{X}$ & Retarding force on the fluid $(\mathrm{N})$ \\
\hline 843 & $f$ & Coriolis parameter $\left(\mathrm{rads}^{-1}\right)$ \\
\hline 844 & $f_{X}$ & Horizontal Reynolds stress in $\mathrm{x}$ direction $\left(\mathrm{ms}^{-2}\right)$ \\
\hline 845 & $M$ & Grid cell coordinate (x direction) $(\mathrm{m})$ \\
\hline 846 & $M_{\xi}$ & Source or sink of momentum in $\xi$ (or $\mathrm{x}$ ) direction $\left(\mathrm{ms}^{-2}\right.$ ) \\
\hline 847 & $N$ & Grid cell coordinate (y direction) $(\mathrm{m})$ \\
\hline 848 & $n$ & Manning's resistance coefficient \\
\hline 849 & $P_{e x}$ & Energy extraction $\left(\mathrm{Js}^{-1}\right)$ \\
\hline 850 & $Q$ & Global source or sink per unit area $\left(\mathrm{kgm}^{-2}\right)$ \\
\hline 851 & $T$ & Thrust coefficient \\
\hline 852 & TEC & Tidal energy converter \\
\hline 853 & $U$ & Horizontal velocity component (x direction) $\left(\mathrm{ms}^{-1}\right)$ \\
\hline 854 & $u$ & Velocity point of the computational cell at location $m$ \\
\hline 855 & $U(z)$ & Current velocity at height $\mathrm{z}$ from the bed $\left(\mathrm{ms}^{-1}\right)$ \\
\hline 856 & $U_{D}$ & Velocity deficit $\left(\mathrm{ms}^{-1}\right)$ \\
\hline 857 & $U_{\text {In }}$ & Flow velocity $\left(\mathrm{ms}^{-1}\right)$ \\
\hline 858 & $U_{\max }$ & Flow nominal velocity $\left(\mathrm{ms}^{-1}\right)$ \\
\hline 859 & $U_{T}$ & Flow velocity after TEC operation $\left(\mathrm{ms}^{-1}\right)$ \\
\hline 860 & $\dot{u}_{i n}$ & Flow acceleration $\left(\mathrm{ms}^{-2}\right)$ \\
\hline 861 & $\mu$ & Kinematic water viscosity $\left(\mathrm{m}^{2} \mathrm{~s}^{-1}\right)$ \\
\hline 862 & $v_{h}$ & Horizontal eddy viscosity coefficient $\left(\mathrm{m}^{2} \mathrm{~s}^{-1}\right)$ \\
\hline 863 & $T$ & Period (hour) \\
\hline
\end{tabular}




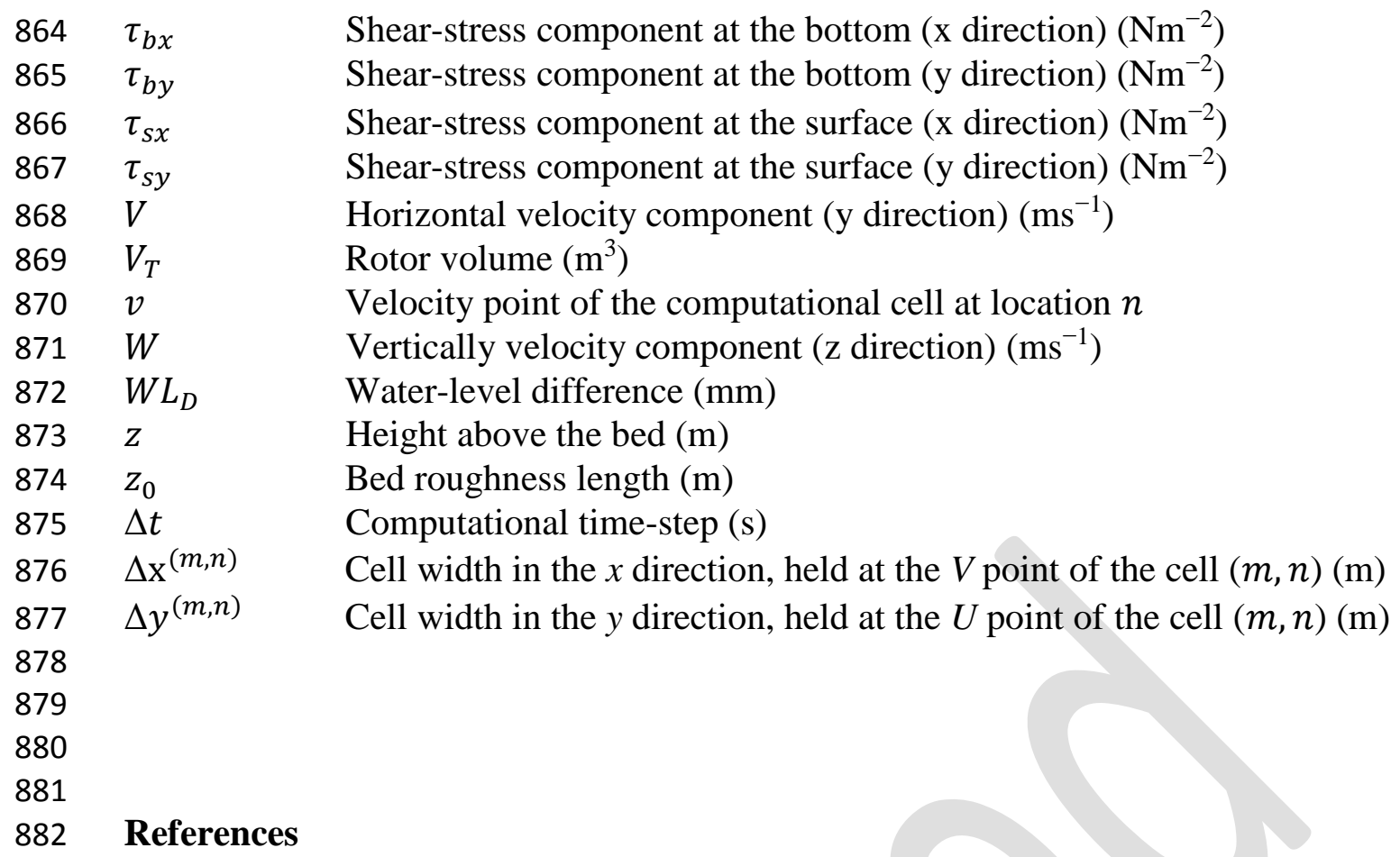

883 [1] Rourke, F.O., Boyle, F., Reynolds, A., 2010. Tidal Energy Update 2009. Appl. Energy 87(2): 398-409 (doi:10.1016/j.apenergy.2009.08.014).

[2] Karsten, R. H., McMillan, J. M., Lickley, M. J., Haynes, R. D. 2008. Assessment 886 of Tidal Current Energy in the Minas Passage, Bay of Fundy. Proceedings of the Institution of Mechanical Engineers, Part A: J. Power and Energy 222: 493-507 (doi:10.1243/09576509JPE555).

[4] Blanchfield, J., Garret, C., Wild, P., Rowe, A., 2008a. The extractable power from 893

[5] Blanchfield, J., Garret, C., Rowe, A, Wild, P., 2008b. Tidal stream power resource 896 assessment for Masset sound, Haida Gwaii. Proc. IMechE, Part A: J.Power and Energy 222: 485-492 (doi:10.1243/09576509JPE585).

[6] Neill, S.P., Litt, E.J. Couch, S.J., Davis, A.G., 2009. The impact of tidal stream turbines on large-scale sediment dynamics. Renew. Energy 34: 2803-2812 (doi:10.1016/j.renene.2009.06.015). 
901

902

903

904

905

906

907

908

909

910

911

912

913

914

915

916

917

918

919

920

921

922

923

924

925

926

927

928

929

930

[7] Sanchez, M., Carballo, R., Ramos, V., Iglesia, G., 2013. Tidal stream energy impact on the transient and residual flow in an estuary: A 3D analysis. Appl. Energy 116: 167-177 (doi:10.1016/j.apenergy.2013.11.052).

[8] Vennell, R., Funke, S.W, Draper, S., Stevens, C., Divett, T. (2015). Designing large arrays of tidal turbines: A synthesis and review. Renewable \& Sustainable Energy Reviews 41: 454-472 (doi:10.1016/j.rser.2014.08.022).

[9] Baxter, J.M., Boyd, I.L., Cox, M., Donald, A.E., Malcolm, S.J., Miles, H., Miller, B., Moffat, C.F., 2011. Scotland's Marine Atlas: Information for the national marine plan. Marine Scotland, Edinburgh. 191 pp.

[10] Woolf, D.K., Challenor, P.G., 2002. Variability and predictability of the North Atlantic wave climate. J. Geophys. Res. (C Oceans) 107 NoC10 - 3145 (doi: 10.1029/2001JC001124).

[11] OSPAR, 2010. Quality Status Report 2010. OSPAR Commission. London. $176 \mathrm{pp}$.

[12] Neill, S.P., Lewis, M.J., Hashemi, N.J., Slater, E., Lawrence, J., Spall, S.A., 2014. Inter-annual and inter-seasonal variability of the Orkney wave power resource. Appl. Energy 132: 339-348 (doi:10.1016/j.apenergy.2014.07.023).

[13] Neill, S.P., Hashemi, M.R., 2013. Wave power variability over the northwest European shelf seas. Appl. Energy 106: 31-46 (doi:10.1016/j.apenergy.2013.01.026).

[14] IACMST, 2005. Inter-Agency Committee on Marine Science and Technology. Marine Processes and Climate, Report n², 139 pp.

[15] SKDT, 2010. South Kintyre Developing Trust - Tidal Energy Feasibility Study. Aquamarine Power Ltd. Report, Stage 1. 58 pp.

[16] Mackie, G., 2008. Development of Evopod tidal stream turbine. In Proc. Int. Conference on Marine Renewable Energy. The Royal Institute of Naval Architects, London.

[17] Delft3D-Flow User Manual, 2011. Simulation of multi-dimensional hydrodynamic and transport phenomena, including sediments. HydroMorphodynamics, $688 \mathrm{pp}$. 
931

932

933

934

935

936

937

938

939

940

941

942

943

944

945

946

947

948

949

950

951

952

953

954

955

956

957

958

959

960

[18] Stelling G.S., Lendertse, J.J., 1991. Approximation of convective processes by cyclic ACI methods. In: Proceedings 2nd ASCE Conference on Estuarine and Coastal Modelling, Tampa, USA.

[19] Soulsby, R.L., 1997. Dynamics of marine sands. A manual for practical applications. HR Wallingford Report SR 466. 142 pp.

[20] Lin, J., Sun, J., Liu, L., Chen, Y., Lin, B., 2015. Refined representation of turbines using a 3D SWE model for predicting distributions of velocity deficit and tidal energy density. Int. J. Energy Res. 39(13): 1828-1842 (doi:10.1002/er.3333).

[21] Sun, X., Chick J.P., Bryden, I.G., 2008. Laboratory-scale simulation of energy extraction from tidal currents. Renew. Energy 33(6): 1267-74 (doi:10.1016/j.renene.2007.06.018).

[22] Whelan, J.I., Graham, J.M.R., Peiró, J., 2009. Inertia effects on horizontal axis tidal-stream turbines. Proceedings of the $8^{\text {th }}$ European Wave and Tidal Energy Conference, Uppsala, Sweden: 586-591.

[23] Draper, G. T., Houlsby, M. L. G., Oldfield, A. G. L., Borthwick, 2009. Modelling tidal energy extraction in a depth-averaged coastal domain. Proceedings of the $8^{\text {th }}$ European Wave and Tidal Energy Conference, Uppsala, Sweden: 1045-1052.

[24] Bahaj, A.S., Batten, W.M.J., McCann, G., 2007. Experimental verifications of numerical predictions for the hydrodynamic performance of horizontal axis marine current turbines. Renew. Energy 32: 2479-2490 (doi:10.1016/j.renene.2007.10.001).

[25] Baston, S., Waldman, S., Side, J., 2014. Modelling energy extraction in tidal flows. An Ouput of TeraWatt Project. 39 pp.

[26] Mohamad, D., 2006. The Evopod Marine Current Turbine. MSc Thesis in Renewable Energy (REFLEX), Newcastle University, 56 pp.

[27] Politis, N., 2010. Incorporating a diffuser on a horizontal axis turbine (Evopod). MSc Thesis in Renewable Energy (REFLEX), Newcastle University, 112 pp.

[28] Work, P.A., Hass, K.A., Defne, Z., Gay, T., 2013. Tidal stream energy site assessment via three-dimensional model and measurements. Appl. Energy 102: 510-519 (doi:10.1016/j.apenergy.2012.08.040). 
961

962

963

964

965

966

967

968

969

970

971

972

973

974

975

976

977

978

979

980

981

982

983

984

[29] Fairley I., Evans P.S., Wooldridge C.F., Willis M., Masters I., 2013. Evaluation of tidal stream resource in a potential array area via direct measurements. Renew. Energy 57: 70-78 (doi:10.1016/j.renene.2013.01.024).

[30] Neill, S.P., Jordan, J.R., Couch, S.J., 2012. Impact of tidal energy converter (TEC) arrays on the dynamics of headland sand banks. Renew. Energy 37: 387397 (doi:10.1016/j.renene.2011.07.003)

[31] Pacheco, A., Ferreira, Ó., Carballo, R., Iglesias, G., 2014. Evaluation of the tidal stream energy production at an inlet channel coupling field data and modelling. Energy 71: 104-117 (doi:10.1016/j.energy.2014.04.075).

[32] Evans, P., Mason-Jones, A., Wilson, C., Wooldridge, C., O’ Doherti, T., O’ Doherti, D., 2015. Constrains on extractable power from energetic tidal straits. Renew. Energy 81: 707-722 (doi:10.1016/j.renene.2015.03.085).

[33] Osalusi, E., Side, J., Harris, R., 2009. Reynolds stress and turbulence estimates in bottom boundary layer of fall of warness. Int. Comm. Heat Mass Transfer Transfer 36 (5): 412-421 (doi:10.1016/j.icheatmasstransfer.2009.02.004).

[34] Osalusi, E., Side, J., Harris, R., 2009. Structure of turbulent flow in EMEC's tidal energy test site. Int. Comm. Heat Mass Transfer Transfer 36 (5): 422-431 (doi:10.1016/j.icheatmasstransfer.2009.02.010).

[35] Waggitt JJ, Bell PS, Scott BE. 2014. An evaluation of the use of shore-based surveys for estimating spatial overlap between deep-diving seabirds and tidal stream turbines. Int. J. Mar. Energy 8: 36-49 (doi:10.1016/j.ijome.2014.10.004).

[36] Edmunds M, Malki R, Williams AJ, Masters I, Croft TN. 2014. Aspects of Tidal Stream Turbine Modelling in the Natural Environment Using a Coupled BEMCFD Model. Int. J. Mar. Energy 7: 20-42 (doi:10.1016/j.ijome.2014.07.001). 